\title{
Liquefaction Potential of Recent Fills versus Natural Sands Located in High-Seismicity Regions Using Shear-Wave Velocity
}

\author{
R. Dobry, M.ASCE${ }^{1}$; T. Abdoun, M.ASCE${ }^{2}$; K. H. Stokoe II, M.ASCE ${ }^{3}$; R. E. S. Moss, M.ASCE${ }^{4}$; \\ M. Hatton, A.M.ASCE${ }^{5}$; and H. El Ganainy, A.M.ASCE
}

\begin{abstract}
The liquefaction potential of clean and silty sands is examined on the basis of the field measurement of the shear-wave velocity, $V_{s}$. The starting point is the database of 225 case histories supporting the Andrus-Stokoe $V_{s}$-based liquefaction chart for sands, silts, and gravels. Only clean and silty sands with nonplastic fines are considered, resulting in a reduced database of 110 case histories, which are plotted separately by type of deposit. A line of constant cyclic shear strain, $\gamma_{c l} \approx 0.03 \%$, is recommended for liquefaction evaluation of recent uncompacted clean and silty sand fills and earthquake magnitude, $M_{\mathrm{w}}=7.5$. The geologically recent natural silty sand sites in the Imperial Valley of southern California have significantly higher liquefaction resistance as a result of preshaking caused by the high seismic activity in the valley. A line of constant cyclic shear strain, $\gamma_{c l} \approx 0.1-0.2 \%$, is recommended for practical use in the Imperial Valley. Additional research including revisiting available $V_{s}$-based and penetration-based databases is proposed to generalize the results of the paper and develop liquefaction charts that account more realistically for deposit type, seismic history, and geologic age.
\end{abstract}

\section{Introduction}

Liquefaction of saturated sands has caused significant damage in dozens of earthquakes, most recently in Haiti (Green et al. 2011; Olson et al. 2011), Chile [Geoengineering Extreme Events Reconnaissance (GEER) 2010b], Japan (GEER 2011b), and New Zealand (GEER 2010a, 2011a). The simplified procedure, originally developed by Seed and Idriss (1971) using the blow count from the standard penetration test (SPT), is widely used for evaluating liquefaction potential of soils in the field. In this method, the shear loading imposed on the soil by the shaking is represented by the cyclic stress ratio (CSR). This is defined as CSR $=\tau_{c} / \sigma_{v 0}^{\prime}$, where $\tau_{\mathrm{c}}=$ representative cyclic shear stress amplitude applied by the earthquake shaking to the liquefiable layer; and $\sigma_{v 0}^{\prime}=$ effective vertical overburden pressure acting on the layer before the earthquake.

\footnotetext{
${ }^{1}$ Institute Professor, Dept. of Civil and Environmental Engineering, Rensselaer Polytechnic Institute, 110 8th St., JEC 4049, Troy, NY 12180 (corresponding author). E-mail: dobryr@rpi.edu

${ }^{2}$ Iovino Chair Professor, Dept. of Civil and Environmental Engineering, Rensselaer Polytechnic Institute, 110 8th St., JEC 4049, Troy, NY 12180.

${ }^{3}$ Jennie C. and Milton T. Graves Chair, Dept. of Civil Engineering, Univ. of Texas at Austin, Austin, TX 78712.

${ }^{4}$ Associate Professor, Dept. of Civil and Environmental Engineering, California Polytechnic State Univ., San Luis Obispo, CA 93407.

${ }^{5}$ Geotechnical Engineer, Haley \& Aldrich, Inc., 3 Bedford Farms Dr., Bedford, NH 03110.

${ }^{6}$ Project Engineering Associate, Paul C. Rizzo Associates, Inc., 500 Penn Center Blvd., Penn Center East, Bldg. 5, Ste. 100, Pittsburgh, PA 15235.
}

In most applications, the CSR is estimated from the following approximate expression:

$$
\left.\mathrm{CSR}=0.65\left(\frac{a_{\max }}{g}\right) \frac{\sigma_{\nu 0}}{\sigma_{v 0}^{\prime}}\right) k_{d}
$$

where $a_{\max }=$ peak horizontal ground surface acceleration; $g=$ acceleration of gravity; $\sigma_{v 0}=$ total vertical overburden pressure at the same depth as $\sigma_{v 0}^{\prime}$; and $r_{d}=$ shear stress reduction coefficient, which is unity at the ground surface and decreases with the depth of the layer. The application of Eq. (1) is equivalent to assuming that the value of the representative cyclic shear stress amplitude, $\tau_{c}$, is $65 \%$ of the maximum cyclic shear stress in the same layer, i.e., $\tau_{\max }$ $=\left(a_{\max } / g\right) \sigma_{v 0} r_{d}$.

A number of popular liquefaction charts have been developed based not only on the SPT but also on other field tests such as the cone penetration test $(\mathrm{CPT})$ and the shear-wave velocity $\left(V_{s}\right)$. Fig. 1 shows a chart based on $V_{s}$ proposed by Andrus and Stokoe (2000). The simplified procedure has been revised and updated a number of times with more case histories, refinements, and corrections [Seed et al. 1983; National Research Council (NRC) 1985; Youd et al. 2001; Cetin et al. 2004; Idriss and Boulanger 2004, 2008; Moss et al. 2006].

Several authors have pointed out some limitations of the charts, such as the following: (1) they are essentially empirical; (2) they provide a lower bound for the occurrence of liquefaction and are by definition conservative; (3) they do not account for the geologic setting and loading history of the sand layer; and (4) they do not address the consequences of liquefaction (Youd et al. 2001, 2003; Pyke 2003; Dobry and Abdoun 2011). The use of the CSR in the charts, though convenient, makes it difficult to correlate them with small-sample laboratory cyclic testing. This difficulty is a result of the fact that pore pressure buildup in both the laboratory and field is more uniquely related to cyclic shear strain than to cyclic shear stress 


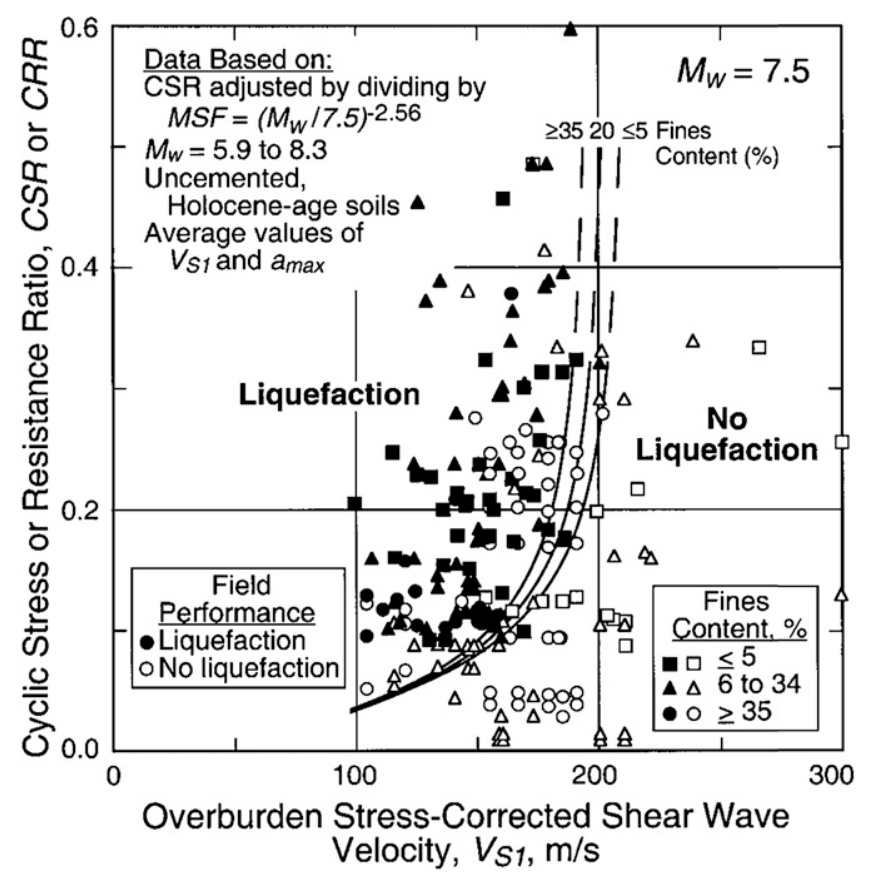

Fig. 1. Original liquefaction chart for sands, silts, and gravels based on field shear-wave velocity, 225 case histories (reprinted from Andrus and Stokoe 2000, (C) ASCE)

(Seed et al. 1983; Dobry and Abdoun 2011; Abdoun et al. 2013). Furthermore, with the possible exception of expensive frozen sampling (Boulanger and Idriss 2011), in most cases it is essentially impossible to obtain undisturbed sand samples that preserve the information about geologic age, loading history, and shaking by previous earthquakes critical to a correct measurement of their liquefaction resistance in the laboratory (see Peck 1979).

Shear wave velocity-based liquefaction charts (such as that shown in Fig. 1) offer the opportunity to improve this situation because of the fact that $V_{s}$ of the soil constitutes a direct field measurement of its small-strain shear modulus, $G_{\max }$, through the basic expression

$$
G_{\max }=\rho V_{s}^{2}
$$

which assumes isotropic linear elasticity. In Eq. (2), $\rho$ denotes mass density, typically obtained from the total unit weight of the saturated soil divided by the acceleration of gravity. That is, for very small cyclic shear strains (e.g., $\gamma_{c} \quad 0.001 \%$ ), $G_{\max }$ and $V_{s}$ are the parameters that directly link the shear stress with the shear strain: $\tau_{c}=G_{\max } \gamma_{c}=\rho V_{s}^{2} \gamma_{c}$. Therefore, parameter $V_{s}$ allows bringing suggestions and ideas originally derived from laboratory studies involving both very small and somewhat larger values of $\gamma_{c}$ to the improvement of liquefaction charts involving case histories characterized by $\tau_{c}$ and CSR $=\tau_{c} / \sigma_{v 0}^{\prime}=0.65\left(a_{\max } / g\right)\left(\sigma_{v 0} / \sigma_{v 0}^{\prime}\right) r_{d}$.

One of these suggestions based on the cyclic strain approach (Dobry and Abdoun 2011), is that recent uncompacted artificial sandy fills should be considered separately from natural sandy soils in high-seismicity areas, and that sands should be considered separately from gravels. The expectation is that the natural sand layers should have a greater resistance to liquefaction because of the interlocking and/or cementation of neighboring sand grains associated with their extended time under static pressure as well as by preshaking as a result of previous earthquakes. This suggestion is pursued herein, taking advantage of the information on deposit type, geologic setting, and age of the liquefiable layers contained in the original database that supported the Andrus-Stokoe chart in Fig. 1 (Andrus et al. 2003).

\section{Andrus and Stokoe Chart}

The $V_{s}$-based liquefaction chart in Fig. 1 was the culmination of an effort that started with evaluation of liquefaction performance during earthquakes at sites in the Imperial Valley in southern California by Bierschwale and Stokoe (1984). A preliminary $V_{s}$-based liquefaction chart calibrated with a few case histories of liquefaction was proposed by Robertson et al. (1992). Systematic compilation of other case histories allowed development by Andrus and Stokoe (2000) of the chart in Fig. 1, which is valid for clean and silty sands as well as gravelly sands and gravels. The chart contains 225 data points, corresponding to sites in California, Idaho, Japan, Taiwan, and China. The chart is supported by a detailed table of the characteristics of these sites, including the measured average $V_{s}$ and normalized shear-wave velocity $\left(V_{s 1}\right)$ for the critical layer at all sites, which is listed in a separate publication (Andrus et al. 2003). The normalized wave velocity is defined as

$$
\left.V_{s 1}=V_{s} \frac{100}{\sigma_{v 0}^{\prime}}\right)^{0.25}
$$

where $V_{s 1}$ and $V_{s}$ are in meters per second and $\sigma_{v 0}^{\prime}$ is in kilopascals. Eq. (3) is based on many laboratory studies showing that $V_{s}$ in sand is approximately proportional to $\left(\sigma_{0}^{\prime}\right)^{0.25}$, where $\sigma_{0}^{\prime}$ is the effective isotropic confining pressure (e.g., Richart et al. 1970). The chart in Fig. 1 and the corresponding $V_{s}$-based method were included as one of the techniques recommended for application of the simplified procedure, along with the SPT and the CPT, by the workshop reported in Youd et al. (2001). Some advantages of using $V_{s}$ instead of penetration resistance are the following: (1) $V_{s}$ can be measured in soils that are difficult to penetrate with the SPT and CPT, such as gravels and gravelly sands; (2) $V_{s}$ can be measured on small samples in the laboratory; and (3) $V_{s}$ has an important physical meaning by constituting a direct measure of the small-strain shear stiffness of the soil [Eq. (2)] compared with SPT and CPT, which are index tests.

The boundary line labeled $\leq 5 \%$ fines in Fig. 1 was proposed by Andrus and Stokoe (2000) for clean uncemented sands or gravels that are less than 10,000 years old (Holocene soils and artificial fills), and is defined by the following equation:

$$
\mathrm{CRR}=\operatorname{MSF}\left[0.022\left(\frac{V_{s 1}}{100}\right)^{2}+\frac{2.8}{\left(215-V_{s 1}\right)}-0.013\right]
$$

where $\mathrm{CRR}=$ cyclic resistance ratio; and $\mathrm{MSF}=$ magnitude scaling factor, which for a given earthquake moment magnitude, $M_{w}$, is given by the following expression (Andrus and Stokoe 2000):

$$
\mathrm{MSF}=\left(\frac{M_{\mathrm{w}}}{7.5}\right)^{-2.56}
$$

In Fig. $1, M_{\mathrm{w}}=7.5$ and MSF $=1$. When using the chart in Fig. 1, CSR $>$ CRR (cyclic stress greater than cyclic resistance) is interpreted to mean that the demand is greater than the resistance and the site will liquefy if subjected to the earthquake represented by the CSR.

Fig. 2 includes a comparison between the Andrus and Stokoe clean sand curve in Fig. 1 for $M_{\mathrm{w}}=7.5$, and the shear wave velocitybased liquefaction chart proposed recently for deterministic evaluations 


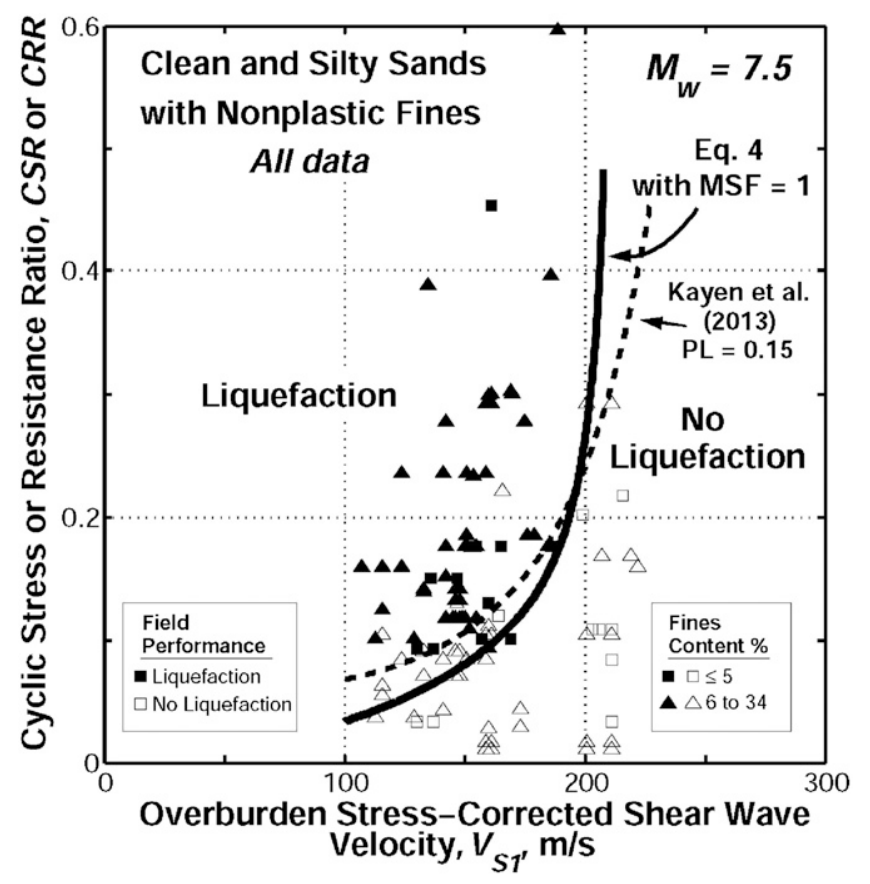

Fig. 2. Case histories of clean and silty sands of $\mathrm{FC} \leq 34 \%$ : all data (110 case histories)

by Kayen et al. (2013). The Kayen et al. (2013) curve is based on a probabilistic study of a very extensive database of 422 case histories from North America, Asia, and Europe, and corresponds to a probability of liquefaction triggering of $15 \%$. Similar to the Andrus and Stokoe (2000) investigation, the Kayen et al. (2013) study included a variety of soils ranging from clean and silty sands to gravels. While generally similar in shape and location, the AndrusStokoe and Kayen et al. curves in Fig. 2 exhibit a couple of important differences. These differences are the following: (1) the Kayen et al. (2013) curve gives liquefaction resistance values that are approximately twice those from the Andrus-Stokoe curve at low values of $V_{s 1}\left(\mathrm{CRR}=0.067\right.$ compared with 0.033 for $\left.V_{s 1}=100 \mathrm{~m} / \mathrm{s}\right)$; and (2) the Kayen et al. (2013) curve allows for the possibility of liquefaction for values of $V_{s 1}>215 \mathrm{~m} / \mathrm{s}$, which is the upper limit proposed by Andrus and Stokoe (2000) for clean sands. As a result, the two curves cross at a point where $V_{s 1}$ is slightly below $200 \mathrm{~m} / \mathrm{s}$.

While the Kayen et al. (2013) database is more extensive, it does not include two key aspects that are critical to this study and are present in the Andrus et al. (2003) database. These key aspects are (1) identification of the soil type in the critical liquefaction layer [clean sand, silty sand, gravel, clayey sand, etc., as well as the fines content (FC) of the soil]; and (2) the geologic origin of the soil [uncompacted fill (UF), compacted fill (CF), natural soil (NS)]. Because of this, only case histories from Andrus et al. (2003) are considered herein, except for an additional case history corresponding to one of the same sites subjected to an earthquake in 2010.

The effect of nonplastic FC in Fig. 1 deserves special consideration. The three curves corresponding to various FCs in Fig. 1 are very close, suggesting that liquefaction triggering is relatively insensitive to $\mathrm{FC}$ when $V_{s}$ is used to quantify liquefaction resistance. This was confirmed by Kayen et al. (2013) in their study, in which it was concluded that the FC had very little effect on the location of the line separating liquefaction from no liquefaction. This insensitivity of the field liquefaction resistance to the FC in the field for a given $V_{s}$ is also consistent with a number of laboratory, centrifuge, and largescale testing results showing the insensitivity to the FC of relevant stress-strain and liquefaction parameters in sands up to FC =30-40\% (see Vucetic 1986; Darendeli 2001; Hsu and Vucetic 2004; Dobry and Abdoun 2011; Umberg 2012; Abdoun et al. 2013; Dobry et al. 2013).

One of the concerns raised about the use of $V_{s}$ has been that this parameter measures the very small-strain properties of the soil in the field $\left(\gamma_{c}, 0.001 \%\right)$ - unlike penetration resistance, which is a measure of the soil strength and other large-strain properties. In this argument, the SPT and CPT should be more relevant to liquefaction, which typically also involves large deformations and strains. However, as shown by Dobry and Abdoun (2011), the Andrus and Stokoe (2000) equations for the curves in their liquefaction chart indicate that the corresponding triggering of liquefaction is associated with relatively small cyclic shear strains of the order of $0.03-$ $0.3 \%$ for earthquakes of magnitude 6 and above. At these small shear strain levels, $V_{s}$ and $G_{\max }$ are good measures of the secant shear modulus of the sand, $G=\tau_{c} / \gamma_{c}$, after applying a correction for soil nonlinearity. This relevant measure is in contrast to the situation for much larger cyclic strains, $\gamma_{c}>1 \%$, where $G_{\max }$ may have to be reduced by $80 \%$ or more to calculate $G$, thus rapidly increasing the uncertainty involved in estimating $G$ from the measured $G_{\max }$.

Another concern has been the presence in Fig. 1 of a number of false positives, that is, points plotted above the curves for sites that did not liquefy despite the chart predicting liquefaction (Liu and Mitchell 2006; Idriss and Boulanger 2008). Liu and Mitchell (2006) attributed some of the false positives to either the presence of a thick surface layer of nonliquefiable soil at some sites or to the effect of nonplastic fines. Hossain et al. (2013) recently found that a few of these false positives can be explained by unsaturated conditions. The existence of some false positives is to be expected in a liquefaction chart such as shown in Fig. 1, where a large number of case histories are plotted together that correspond to a wide variety of soils and circumstances. On the other hand, it is desirable to reduce the number of these false positives as much as possible through better understanding of the factors controlling the chart, with corresponding improved predictive power. This improved understanding and the reduction in the number of false positives are accomplished in this paper, first by separating the sands from the gravels and other soils, and then by segregating the sands by type of deposit. As shown herein, the false positives in Fig. 1 for clean and silty sands tend to disappear when the uncompacted artificial fills and natural sand sites are considered separately.

Specifically, only clean and silty sands up to $\mathrm{FC}=34 \%$ are considered herein. The corresponding case histories for these materials are obtained from the Andrus et al. (2003) database that supports Fig. 1. Based on the previous discussion, it is assumed that the liquefaction/ no-liquefaction boundary is independent of the FC for this range of FC. The curve labeled $\leq 5 \%$ fines in Fig. 1, defined by Eq. (4) and $\mathrm{MSF}=1$, is used as a starting point for both clean and silty sands.

\section{Liquefaction Charts as Lines of Constant Cyclic Shear Strain}

Seed et al. (1983) and Dobry (1989) suggested that the lower end of liquefaction charts based on penetration resistance are lines of constant cyclic shear strain. As pointed out by Andrus and Stokoe (2000), the form of Eq. (4) is explicitly designed to follow a line of constant cyclic shear strain in the CRR versus $\gamma_{c}$ graph in Fig. 1, as the value of $V_{s 1}$ approaches zero. That is, at very small values of $V_{s 1}$, the second and third terms of the equation cancel each other, only the first term is left, and the corresponding parabola CRR $=0.022 \operatorname{MSF}\left(V_{s 1} / 100\right)^{2}$ is a line of constant $\gamma_{c}$ (see Dobry and Abdoun 2011; Schneider and Moss 2011). 
This constant strain relationship can be developed by recalling the basic definition of CSR $=\tau_{c} / \sigma_{v 0}^{\prime}$, combined with the definition of the secant modulus of the sand, $G=\tau_{c} / \gamma_{c}=\left(G / G_{\max }\right)_{c} G_{\max }$, where $\left(G / G_{\max }\right)_{c}$ is the value of the modulus reduction curve of the soil corresponding to a strain $\gamma_{c}$ (Seed and Idriss 1970; Darendeli 2001). This substitution results in $\operatorname{CSR}=\left(G / G_{\max }\right)_{c} \gamma_{c} G_{\max } / \sigma_{v 0}^{\prime}$. If $G_{\max }$ is replaced in the last expression by $\rho V_{s}^{2}$ [Eq. (2)] and $V_{s}$ by $\left(\sigma_{v 0}^{\prime} / 100\right)^{0.25} V_{s 1}$ [Eq. (3)], the equation becomes CSR $=0.1 \rho$ $\left(G / G_{\max }\right)_{c} \gamma_{c} V_{s 1}^{2} /\left(\sigma_{v 0}^{\prime}\right)^{0.5}$. After replacing CSR by CRR and $\gamma_{c}$ by $\gamma_{c l}$ (where $\gamma_{c l}=\gamma_{c}$ needed for liquefaction), the desired equation is

$$
\mathrm{CRR}=0.1 \rho \frac{\left(G / G_{\max }\right)_{\gamma_{c l}} \gamma_{c l}}{\sqrt{\sigma_{v 0}^{\prime}}} V_{s 1}^{2}
$$

where $\sigma_{v 0}^{\prime}$ is in kilopascals; $\gamma_{c l}$ is in meters per meter; and $V_{s 1}$ is in meters per second. Eq. (6) has the same parabolic form as $\mathrm{CRR}=0.022 \operatorname{MSF}\left(V_{s 1} / 100\right)^{2}$ in Eq. (4) at small $V_{s 1}$. That is, both expressions have the form $\operatorname{CRR}=f\left(\gamma_{c l}\right) V_{s 1}^{2}$, where $f\left(\gamma_{c l}\right)$ is a function of $\gamma_{c l}$. Eq. (6) can be used to show that for the clean sand curve in Fig. 1 and for values of $\sigma_{v 0}^{\prime}$ and $V_{s 1}=100-160 \mathrm{~m} / \mathrm{s}$ relevant to the field case histories, the curve in Fig. 1 follows a line of constant strain, $\gamma_{c l} \quad 0.03 \%$ (see Dobry and Abdoun 2011). This $\gamma_{c l}$ is slightly above the volumetric threshold cyclic shear strain needed to start pore pressure buildup in sands, $\gamma_{t v} \quad 0.01 \%$. The relationship between Eqs. (4) and (6) is further developed subsequently.

\section{Consideration of Only Clean and Silty Sands}

On the basis of this fundamental idea that part of the curve in Fig. 1 should be a line of constant $\gamma_{c l} \quad 0.03 \%$ for clean and silty sands, the authors decided to focus on the clean and silty sands included in the original Andrus et al. (2003) database. This evaluation meant discarding all sites with gravels, gravelly sands, clayey sands, and silts, and considering only the clean sands and silty sands with nonplastic fines.
This analysis was performed by considering only sites in the database corresponding to sands with a silt content up to $\mathrm{FC}=34 \%$. This subset consisted of 109 case histories; approximately half of the 225 case histories in the original database. A nonliquefaction case history corresponding to one of the same sites listed by Andrus et al. (2003), subjected to an earthquake in 2010, was added for a total of 110 case histories. The details of this additional case history are discussed subsequently.

The main features of this database of 110 case histories are summarized in Table 1, which includes earthquakes; earthquake magnitudes; the number of case histories by liquefaction occurrence, FC, NSs, or artificial fills; and the effective vertical stress on the critical layer. Table 1 covers a range of earthquake magnitudes between 5.3 and 8.3, the same as in the original Andrus et al. (2003) database. However, the geographical coverage of the 110 case histories in Table 1 is more restricted, corresponding only to locations in California and Japan. Furthermore, 58 of the 59 case histories associated with NS sites are located in high-seismicity areas of California, such as the greater San Francisco Bay Area, Los Angeles, and Imperial Valley. These locations mean that any conclusion about liquefaction potential of natural soil sites drawn from this database must take into account the possible influence of prior repeated earthquake shaking experienced at sites in northern and southern California. Therefore, any such conclusion may or may not be applicable to NS sites in other regions where earthquakes are less frequent. About one-fourth of the sites in Table 1 corresponds to clean sands with $\mathrm{FC} \leq 5 \%$, while the rest are silty sands with $\mathrm{FC}=6-34 \%$. There are 39 case histories of UFs, with most of them provided by the $1989\left(M_{\mathrm{w}}=7.0\right)$ Loma Prieta Earthquake in northern California. The Loma Prieta event also provides all six cases of CFs.

In Appendix S1, Table $\mathrm{S} 1$ contains a complete list of the 110 case histories, reproducing for each one the most relevant information from the original table provided by Andrus et al. (2003). This information includes the following: (1) the average FC for the critical layer; (2) the deposit type and geologic age of this layer; and (3) the average values of the two parameters for the critical layer needed to

Table 1. Case Histories (110) of Clean and Silty Sands Listed in Table S1 and Used to Establish the CRR- $V_{s 1}$ Curves (Data from Andrus et al. 2003)

\begin{tabular}{|c|c|c|c|c|c|c|c|c|c|c|c|c|c|}
\hline \multirow[b]{3}{*}{ Earthquake } & \multirow[b]{3}{*}{$M_{\mathrm{w}}$} & \multicolumn{12}{|c|}{ Number of case histories by } \\
\hline & & \multicolumn{2}{|c|}{$\mathrm{FC}(\%)$} & \multicolumn{4}{|c|}{ Effective vertical stress, $\sigma_{v 0}^{\prime}(\mathrm{kPa})$} & \multicolumn{4}{|c|}{ Layer type } & \multicolumn{2}{|c|}{ Liquefaction occurrence } \\
\hline & & $\leq 5$ & $6-34$ & $20-60$ & $60-100$ & $100-140$ & $>140$ & UF & $\mathrm{CF}$ & NS & UO & Yes & No \\
\hline 1906 San Francisco, California & 7.7 & - & 4 & - & - & 4 & - & - & - & 4 & - & 4 & - \\
\hline 1957 Daly City, California & 5.3 & 3 & 2 & 1 & 3 & 1 & - & 4 & - & 1 & - & - & 5 \\
\hline 1964 Niigata, Japan & 7.5 & 4 & - & 3 & 1 & - & - & - & - & - & 4 & 3 & 1 \\
\hline 1979 Imperial Valley, California & 6.5 & - & 9 & 9 & - & - & - & - & - & 9 & - & 3 & 6 \\
\hline 1980 Mid-Chiba, Japan & 5.9 & - & 1 & - & 1 & - & - & 1 & - & - & - & - & 1 \\
\hline 1981 Westmorland, California & 5.9 & - & 9 & 9 & - & - & - & - & - & 9 & - & 4 & 5 \\
\hline 1985 Chiba-Ibaragi, Japan & 6.0 & - & 1 & - & 1 & - & - & 1 & - & - & - & - & 1 \\
\hline 1987 Chiba-Toho-Oki, Japan & 6.5 & - & 1 & - & - & 1 & - & 1 & - & - & - & - & 1 \\
\hline 1987 Elmore Ranch, California & 5.9 & - & 9 & 9 & - & - & - & - & - & 9 & - & - & 9 \\
\hline 1987 Superstition Hills, California & 6.5 & - & 9 & 9 & - & - & - & - & - & 9 & - & 3 & 6 \\
\hline 1989 Loma Prieta, California & 7.0 & 19 & 29 & 10 & 33 & 5 & - & 29 & 6 & 13 & - & 35 & 13 \\
\hline 1993 Kushiro-Oki, Japan & 8.3 & 1 & 1 & 2 & - & - & - & 1 & - & 1 & - & 2 & - \\
\hline 1993 Hokkaido-Nansei-Oki, Japan & 8.3 & - & 2 & 2 & - & - & - & - & - & - & 2 & 1 & 1 \\
\hline 1994 Northridge, California & 6.7 & - & 3 & - & 3 & - & - & - & - & 3 & - & 3 & - \\
\hline 1995 Hyogoken-Nanbu, Japan & 6.9 & - & 2 & - & - & 1 & 1 & 2 & - & - & - & 2 & - \\
\hline 2010 El Mayor-Cucupah, Mexico ${ }^{a}$ & 7.2 & - & 1 & 1 & - & - & - & - & - & 1 & - & - & 1 \\
\hline Total & & 27 & 83 & 55 & 42 & 12 & 1 & 39 & 6 & 59 & 6 & 60 & 50 \\
\hline
\end{tabular}

${ }^{a}$ The 2010 El Mayor-Cucupah earthquake occurred in Mexico close to the U.S. border, and the case history site (Wildlife) is located in Imperial Valley, California. 
plot the corresponding data point in a graph such as in Fig. $1\left[(\mathrm{~V})_{s 1}\right.$ and $\left.(\mathrm{CSR})_{7.5}\right]$. These 110 data points are plotted in Fig. 2, together with the Andrus-Stokoe curve corresponding to clean sands, as well as the Kayen et al. (2013) curve. As in Fig. 1, the Andrus-Stokoe curve in Fig. 2 provides a lower bound for cases of liquefaction, and still includes a number of false positives (i.e., sites predicted to liquefy where liquefaction was not observed). The Kayen curve provides a better boundary for the data points in Fig. 2, with only a couple of false positives. Similar to other studies of this kind (e.g., Kayen et al. 2013), each Andrus-Stokoe case history in Figs. 1 and 2 is defined by the combination of an observation of liquefaction or no liquefaction for an earthquake event, and a measurement of $V_{s 1}$ in the critical layer at the same physical site. This combination allows incorporation of the scatter arising from multiple measurements of $V_{s 1}$ in the same layer at one site. However, it also means that Figs. 1 and 2 include more than one data point for the same site and layer subjected to a given earthquake.

\section{Recent UFs, CFs, and NSs}

An important aspect of the original table in Andrus et al. (2003) is that it provides information about the deposit type and geologic age of each site, in which eight types of deposits are listed: fill, hydraulic fill, dumped fill, UF, improved fill, alluvial, alluvial/fluvial, and dunes. In terms of geologic age, the sites are classified as either recent $(<500$ years) or Holocene $(<10,000$ years $)$.

The authors combined all eight deposit types from Andrus et al. (2003) into three broader categories: UF, CF, and NS. The new UF category lumps together the original fill, hydraulic fill, dumped fill, and UF categories. The new NS category lumps together the original alluvial, alluvial/fluvial, and dunes categories. The new CF category corresponds to the original improved fill category in Andrus et al. (2003). A fourth new category labeled unknown origin (UO) was added for the six sites in which it was not possible to determine from the available information if the site was a NS or artificial fill; these six sites of UO are not considered further herein. Finally, any site of Holocene age according to Andrus et al. (2003) was cataloged as a NS even when not clear if it is of alluvial, fluvial, or dune origin.

The authors augmented the original database of 109 case histories from Andrus et al. (2003), with one additional case history of a NS site. This case history is associated with the Wildlife site in southern California, which was shaken by four earthquakes between 1979 and 1987 listed in Table 1 (1979 Imperial Valley, 1981 Westmorland, 1987 Elmore Ranch, and 1987 Superstition Hills). The site liquefied in 1981 and in one of the 1987 earthquakes; however, it did not liquefy in the other two events. The site had been instrumented with accelerometers and piezometers by the USGS in the 1980s, and was reinstrumented in 2005 by the University of California at Santa Barbara with support from the Network for Earthquake Engineering Simulation (NEES) (see Youd et al. 2007; Steidl and Seale 2010). The site was subjected to the El MayorCucupah earthquake $\left(M_{\mathrm{w}}=7.2\right)$ on April 4, 2010, having its epicenter in nearby Baja California, Mexico. The recorded peak ground surface accelerations in the two horizontal directions were 0.145 and $0.124 g$. Based on the measured static pore pressures just before shaking, it was established that the groundwater level was at a depth of approximately $1.0 \mathrm{~m}$ (http://www.nees.ucsb.edu/ facilities/wla; J. M. Steidl, personal communication, 2013). The site did not liquefy and built up a maximum excess pore pressure ratio, $\left(r_{u}\right)_{\max }$, of only $19 \%$. This measurement allowed the authors to generate the additional nonliquefaction case history and to plot it as another data point in Fig. 2. For this case history, $V_{s 1}=147 \mathrm{~m} / \mathrm{s}$ was used, corresponding to the average of the two crosshole measurements at this same site provided in Andrus et al. (2003).
The 104 data points corresponding to these three site categories (UF, CF, and NS), are plotted separately. (These are all of the 110 case histories described previously, minus the six case histories of UO.) Specifically, the UFs are plotted in Fig. 3, with additional information also related to the same UF category included in Figs. 4 and 5. The CF and NS categories are plotted together in Fig. 6. Figs. 3 and 6 include the same original Andrus and Stokoe (2000) curve for the clean sands previously presented in Figs. 1 and 2, corresponding to Eq. (4), as well as the Kayen et al. (2013) curve in Fig. 2.

\section{Recent UFs}

Fig. 3, which contains 39 case histories of clean and silty sands, shows that the original Andrus and Stokoe curve for clean sands separates liquefaction from no liquefaction reasonably well for UFs. Furthermore, unlike the situation in Figs. 1 and 2, Fig. 4 does not exhibit any false positives. The line represented a good lower bound in Figs. 1 and 2 for sites that have experienced liquefaction. However, in Fig. 3, the same line goes a step further by clearly separating the cases of liquefaction and no liquefaction, thus suggesting the line may have improved predictive power for recent UFs. Examination of the data points in Fig. 3, where different symbols are used for FC smaller or greater than 5\%, indicates that the curve may be a reasonable boundary irrespective of the sites being clean or silty sands. This similarity means that, as expected, no systematic difference is observed between sites consisting of clean and silty sands.

In summary, Fig. 3 suggests that when loose, uncompacted recent fills are considered containing only clean or silty sands with nonplastic fines up to $34 \%$, the original clean sand Andrus and Stokoe curve defined by Eq. (4) may be a good predictor of the occurrence of both liquefaction and no liquefaction. This good delineation is in contrast to the curve from Kayen et al. (2013), also included in Fig. 3, which seems to be too high for the UFs - with several false negatives where points are predicted not to liquefy when, in fact, liquefaction

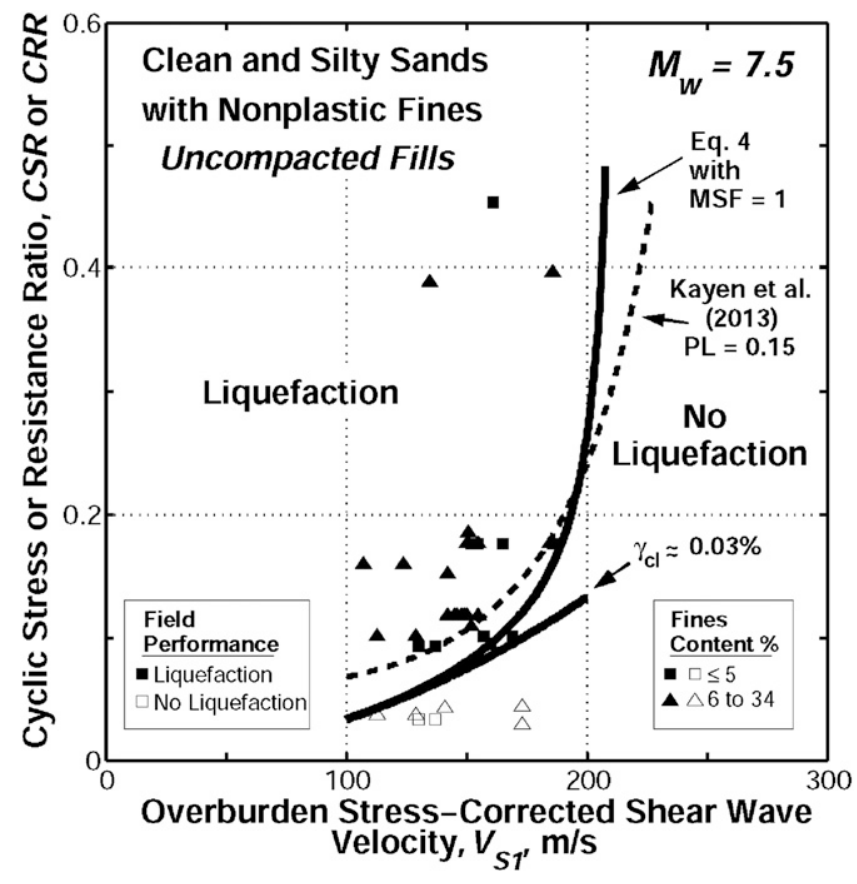

Fig. 3. Case histories of clean and silty sands: uncompacted recent artificial fills (UF, 39 case histories); the curve of $\gamma_{c l} \quad 0.03 \%$ corresponds to Eq. (7) with $\mathrm{MSF}=1$ and $\mathrm{CRR}=0.033\left(V_{s 1} / 100\right)^{2}$ 


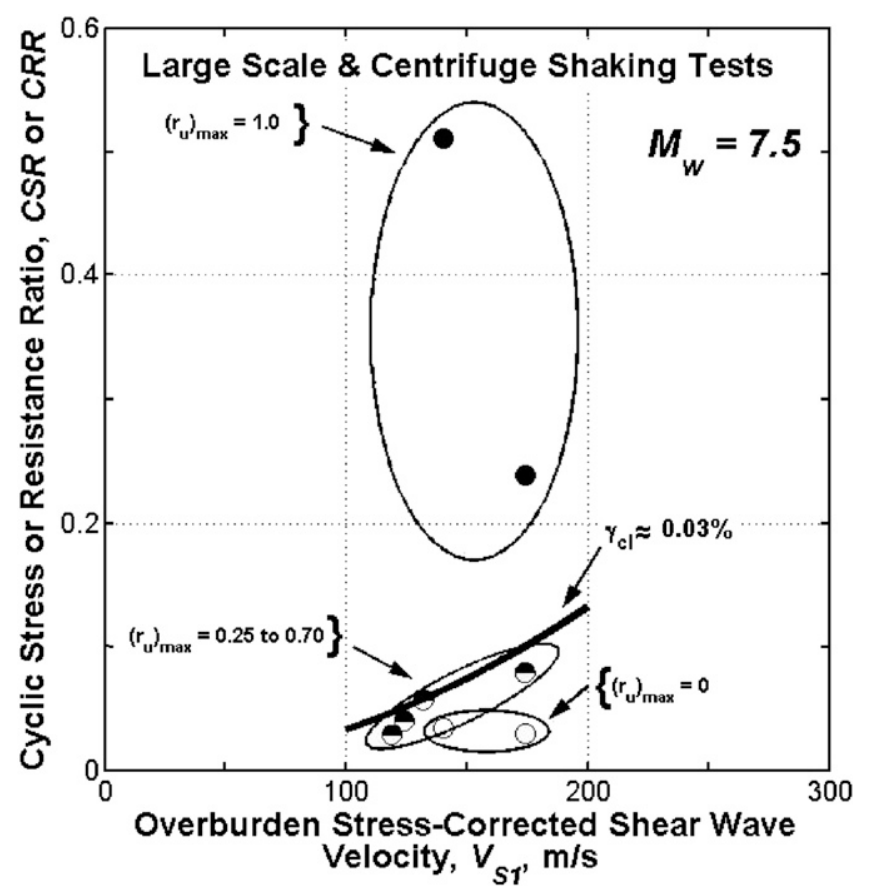

Fig. 4. Laboratory case histories (large-scale and centrifuge tests) of UFs compared with the proposed constant cyclic strain liquefaction chart (data from Dobry et al. 2013): $\left(r_{u}\right)_{\max }=$ maximum pore pressure ratio recorded anywhere in the liquefiable deposit; the curve of $\gamma_{c l}$

$0.03 \%$ corresponds to Eq. (7) with $\mathrm{MSF}=1$ and $\mathrm{CRR}=0.033$ $\left(V_{s 1} / 100\right)^{2}$

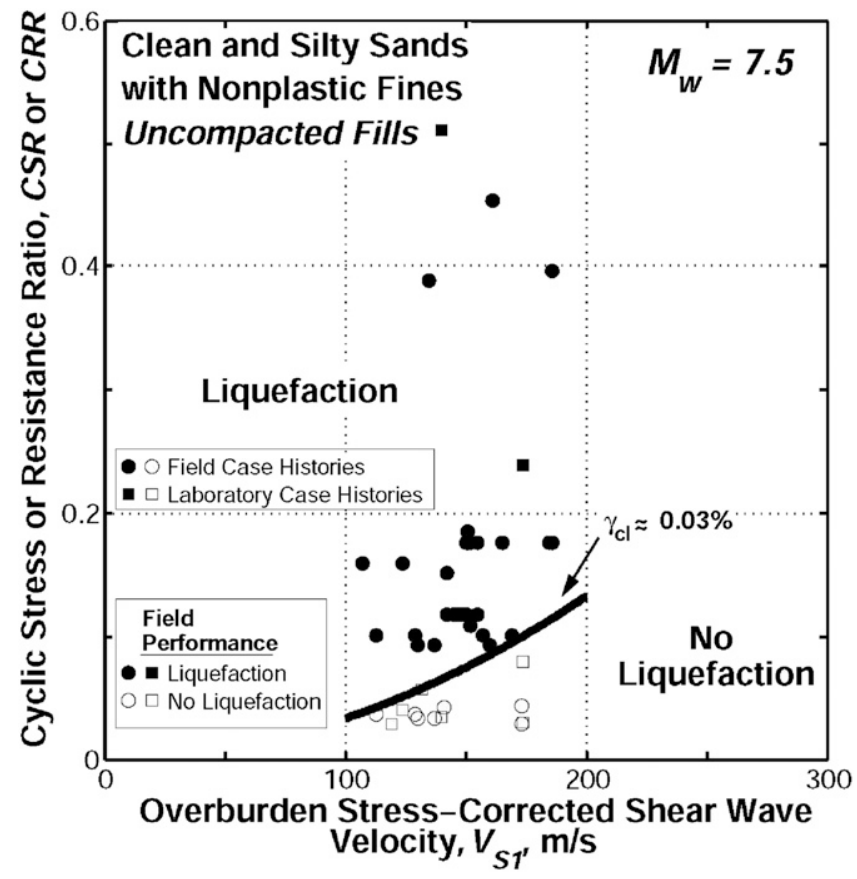

Fig. 5. Proposed constant cyclic shear strain liquefaction chart calibrated with the field case histories of UFs fills from Fig. 3 and supplemented with the laboratory (large-scale and centrifuge) case histories from Fig. 4: the curve corresponds to Eq. (7) with MSF $=1$ and CRR $=0.033\left(V_{s 1} / 100\right)^{2}$, associated with $\gamma_{c l} \quad 0.03 \%$

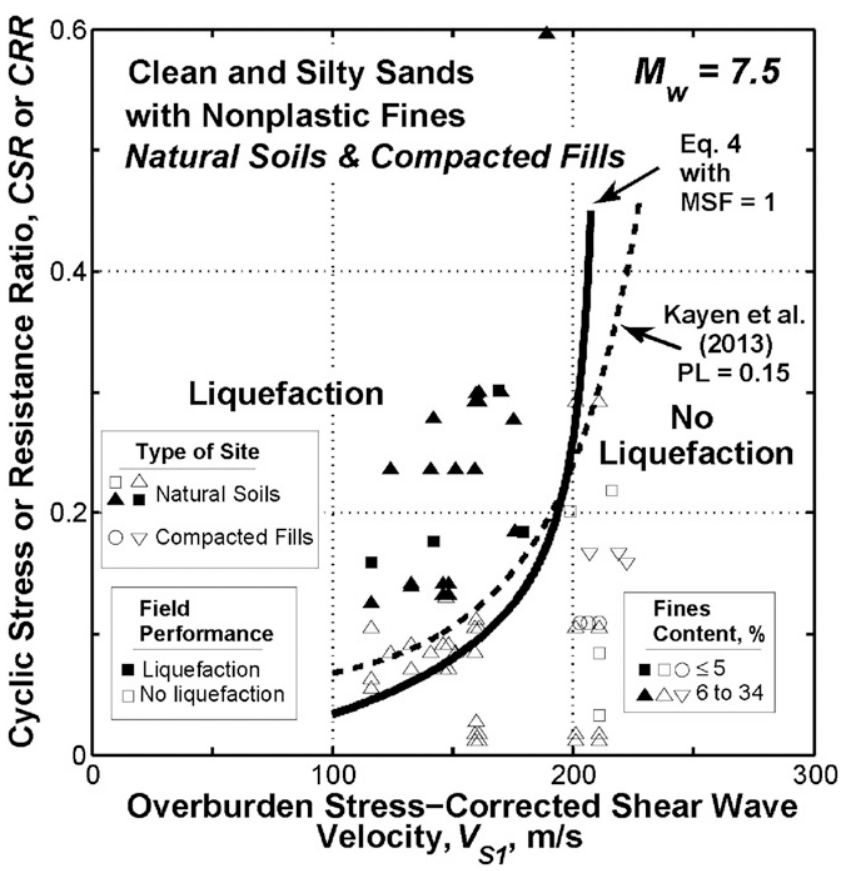

Fig. 6. Case histories of clean and silty sands: compacted recent artificial fills (CF, six case histories) and NSs (NS, 59 case histories)

was observed. However, the comparison in Fig. 3 also shows the following:

1. There are no case histories between CSR $=0.04$ and 0.09 in the database. As a result, Fig. 3 exhibits a gap between these two CSR values, introducing an uncertainty about the exact location of the boundary line. If a curve separating the cases of liquefaction from no liquefaction were to be defined exclusively from the data points in the graph, there is a range in the possible locations for this line, some above and some below the Andrus and Stokoe (2000) curve.

2. The values of $V_{s 1}$ for all case histories of liquefaction and no liquefaction plotted in Fig. 3 are below $190 \mathrm{~m} / \mathrm{s}$. This evidence, plus the experience of the authors in constructing model clean and silty sand deposits in the laboratory for centrifuge and large-scale tests using various depositional methods, indicates that it is very difficult for recent uncompacted sandy fills to have a value of $V_{s 1}$ exceeding $190-200 \mathrm{~m} / \mathrm{s}$. This suggests that the question of liquefaction of these soils with $V_{s 1}$ values above $200 \mathrm{~m} / \mathrm{s}$ may not be of great practical interest.

A more exact location of the boundary curve in Fig. 3 can only be defined with additional case histories of uncompacted sandy fills having CSR values between 0.04 and 0.09 that close the gap. Additional field case histories were not available at the time of this study. However, there are two other tools that can be helpful and were used by the authors to better locate the boundary. These tools are (1) the cyclic strain approach and (2) available centrifuge and large-scale tests on clean and silty sands that provide additional laboratory case histories.

\section{Cyclic Strain Approach}

There is a significant body of experimental evidence in the literature from cyclic strain-controlled laboratory tests and large-scale and centrifuge shaking tests on recent, uncompacted, normally consolidated clean and silty sands. This evidence indicates that for a given number of shaking cycles, a given excess pore pressure ratio $\left(r_{u}\right)$ 
consistently occurs at a specific level of cyclic shear strain, $\gamma_{c}$. This includes the case of liquefaction triggering $\left(r_{u}=1.0\right)$. Some of this evidence that was obtained on various clean and silty sands at a number of laboratories was discussed previously (see Dobry and Abdoun 2011; Abdoun et al. 2013). Because the earthquake magnitude is correlated with the number of shaking cycles (Idriss and Boulanger 2008), these results strongly suggest that the curve separating liquefaction from no liquefaction for $M_{\mathrm{w}}=7.5$ in Fig. 3, associated with approximately 15 cycles of shaking, should be a line of constant $\gamma_{c}=\gamma_{c l}$ for the range of interest, $V_{s 1}=100-200 \mathrm{~m} / \mathrm{s}$. The curve of constant strain associated with $\gamma_{c l} \quad 0.03 \%$ has been added in Fig. 3. This curve corresponds to

$$
\mathrm{CRR}=0.033 \operatorname{MSF}\left(\frac{V_{s 1}}{100}\right)^{2}
$$

where MSF $=1$ in Fig. 3; and $V_{s 1}$ is in meters per second. The factor 0.033 in Eq. (7) was defined such that Eqs. (4) and (7) give the same $\mathrm{CRR}=0.033$ at $V_{s 1}=100 \mathrm{~m} / \mathrm{s}$ when $\mathrm{MSF}=1$. The fact that this curve corresponds to a cyclic shear strain, $\gamma_{c l} \quad 0.03 \%$ for MSF $=1$ and $M_{\mathrm{w}}=7.5$, was established using Eq. (6) with $\sigma_{v 0}^{\prime}=75 \mathrm{kPa}$ and the calculation procedure described by Dobry and Abdoun (2011). Fig. 3 shows that this curve of constant cyclic strain needed for liquefaction (1) is essentially identical to the Andrus and Stokoe curve defined by Eq. (4) up to approximately $V_{s 1}=150-160 \mathrm{~m} / \mathrm{s}$; and (2) also separates well the field cases of liquefaction from no liquefaction.

\section{Large-Scale and Centrifuge Tests}

The available large-scale and centrifuge shaking tests conducted by Abdoun et al. (2013) can be plotted as additional case histories on the liquefaction chart in Fig. 3 to verify if the line of constant strain defined by Eq. (7) is indeed the correct boundary. This comparison is shown in Figs. 4 and 5, which includes eight additional case histories where 6-m-thick homogeneous clean and silty sand deposits were subjected to 10 shaking cycles. Figs. 4 and 5 take advantage of the work published by Dobry et al. (2013), where these same eight laboratory case histories were compared with the field case histories from the Andrus et al. (2003) database corresponding to the 1989 Loma Prieta earthquake $\left(M_{\mathrm{w}}=7.0\right)$. Because this earthquake had a magnitude of $M_{\mathrm{w}}=7.0$, no correction for magnitude was necessary for the experimental duration of the 10 shaking cycles. On the other hand, in Figs. 4 and 5 the CSR values from these eight additional case histories have been converted from $M_{\mathrm{w}}=7.0$ to $M_{\mathrm{w}}=7.5$ through the use of the MSF, defined in Eq. (5). This and other details-including correction of the experimental CSR for two-dimensional shaking in the field-are listed in Table S2, where most of the information was transcribed from Dobry et al. (2013). As indicated in Table S2, the eight case histories included two largescale and six centrifuge tests conducted on two sands (clean sand and silty sand), using hydraulic filling and dry pluviation depositional methods, and covering a range of base accelerations, $a_{\max }=0.014-$ $0.176 \mathrm{~g}$. Two of the deposits liquefied while the other six did not, developing instead a maximum pore pressure ratio in the deposit, $\left(r_{u}\right)_{\max }$, ranging between 0 and 0.7 .

Fig. 4 plots these eight additional large-scale and centrifuge case histories on the same CSR versus $V_{s 1}$ chart corresponding to $M_{\mathrm{w}}=7.5$. Again, and similarly to the field case histories in Fig. 3, the eight laboratory case histories in Fig. 4 have values of $V_{s 1}$ in the range of $100-200 \mathrm{~m} / \mathrm{s}$. The data points are completely consistent with the curve of constant cyclic strain defined by Eq. (7) for this earthquake magnitude, delineating quite well the curve from below with the four tests that developed $\left(r_{u}\right)_{\max }=0.25-0.70$. The two experiments that did not have any pore pressure buildup, $\left(r_{u}\right)_{\max }=0$, were associated with low shear strains below the threshold cyclic shear strain, $\gamma_{c}<\gamma_{t v}=0.01 \%$, and they plot significantly below the curve.

In Fig. 5, these eight additional laboratory case histories are plotted as data points showing only liquefaction or no liquefaction, together with the rest of the field case histories from Fig. 3. Fig. 5 shows that these additional case histories indeed help close the gap discussed previously between CSR $=0.04$ and 0.09 . Once the field and laboratory case histories are considered together in Fig. 5, it becomes difficult to make the case that the correct boundary line should be lower than the constant strain curve. On the other hand, the case could still be made - if only the data points in Fig. 5 are considered - that the correct boundary line may be somewhat higher at low values of $V_{s 1}$. However, as discussed previously, all evidence points to a line of constant strain being the correct boundary for recent UFs.

\section{Recommended Chart for UFs}

The authors recommend the line of constant cyclic strain needed for liquefaction, defined by Eq. (7) and plotted in Fig. 5, to predict occurrence of both liquefaction and no liquefaction of recent, uncompacted sandy fills in the field containing up to approximately $34 \%$ nonplastic fines. This recommendation is valid for $V_{s 1}$ $<200 \mathrm{~m} / \mathrm{s}$. The two related questions of the possible existence of recent uncompacted sandy fills having $V_{s 1}>200 \mathrm{~m} / \mathrm{s}$ and how to evaluate their liquefaction potential are outside the scope of this paper and may be the subject of future research.

\section{CFs}

The case histories of CFs composed of clean and silty sands are included in Fig. 6. There are only six data points, all corresponding to no liquefaction, $V_{s 1}>200 \mathrm{~m} / \mathrm{s}$, and CSR $<0.2$. Both the Andrus and Stokoe (2000) and Kayen et al. (2013) curves in Fig. 6 predict well this no-liquefaction response.

\section{NSs}

The NSs composed of clean and silty sands are also included in Fig. 6. There are 59 case histories of NSs, located mostly in California. Fig. 6 shows that essentially all false positives previously noticed in Fig. 2 for the Andrus and Stokoe curve correspond to NS sites. Furthermore, all false positives in Fig. 6 are silty sands concentrated in a zone just above the original Andrus-Stokoe solid line, with that zone not including any liquefied site. Fig. 6 strongly suggests that the original Andrus-Stokoe boundary solid line, which exhibited reasonably good agreement for the UFs in Fig. 3, may be too conservative and should perhaps be raised for NSs in highly seismic areas. This conclusion is reinforced by the location of the Kayen et al. (2013) dashed line in Fig. 6, which plots higher in the relevant range of $V_{s 1}$ and exhibits only a couple of false positives. Furthermore, the curve of constant shear strain, $\gamma_{c l} \quad 0.03 \%$, in Fig. 3, which was well calibrated with both field case histories and centrifuge and large-scale testing of recent UFs in Fig. 5, would also be a poor predictor of the liquefaction response of the natural sands in Fig. 6, again with many false positives.

Figs. 3, 5, and 6, taken together, are also consistent with reports by other researchers based on their field observations after specific earthquake events, that loose natural sands in active seismic areas of California and Japan having similar penetration resistance may in fact be more resistant to liquefaction than younger artificial fills. Pyke (2003) reported "studies conducted in the alluvial fan deposits 
which surround San Francisco Bay where the simplified procedure has predicted liquefaction for levels of shaking felt in the 1989 Loma Prieta earthquake when, in fact, liquefaction was not observed." More recently, Ishihara et al. (2011) reported the following for Urayasu City, Tokyo Bay, after the 2011 Great East Japan earthquake: "It is of interest to notice that although the SPT $N$-value of 5-15 for the alluvial sand is only slightly larger as compared to $N=5-10$ for the reclaimed sand, the new sand was more vulnerable to liquefaction, as evidenced by the clear manifestation of liquefaction in the reclaimed area in contrast to no liquefaction in the old area in the north" (see Cox et al. 2013).

Fig. 6 is also consistent with a number of field and laboratory studies showing that a number of factors affecting natural sites, such as geologic age, overconsolidation, and preshaking, tend to increase liquefaction resistance (Youd and Hoose 1977; Youd and Perkins 1978; Seed 1979; Troncoso et al. 1988; Arango and Migues 1996; Lewis et al. 1999; Arango et al. 2000; Pyke 2003; Youd et al. 2003; Baxter and Mitchell 2004; Leon et al. 2006; Moss et al. 2008; Heidari and Andrus 2012; Hayati and Andrus 2008, 2009). Fig. 6 may be providing a more precise quantification of the combined effect of some of these factors on natural silty sands in some high-seismicity areas, when the simplified procedure is used in conjunction with $V_{s}$.

\section{Natural Silty Sands in the Imperial Valley of California}

The 13 data points of NSs, which are false positives in Fig. 6 relative to the original Andrus and Stokoe (2000) solid line, correspond to alluvial/fluvial silty sand sites located in two well-defined, highseismicity geographical areas: the Imperial Valley of southern California, and the Salinas River Valley in northern California. Table 1 lists five earthquakes that shook the Imperial Valley sites. Liquefaction occurred at some of the sites for some of the earthquakes. The five earthquakes are the 1979 Imperial Valley, 1981 Westmorland, 1987 Elmore Ranch, 1987 Superstition Hills, and 2010 El Mayor-Cucupah. The Greater San Francisco Bay area site near the Salinas River was subjected to two of the earthquakes listed in Table 1, showing manifestations of liquefaction in the 1906 San Francisco earthquake but not in the 1989 Loma Prieta event.

Detailed examination of the characteristics of these 13 false positives in Table S1 as well as in the original Andrus et al. (2003) database reveals the following two main facts:

1. Two of the case histories (Case History Nos. 71 and 72 in Table S1), correspond to the Salinas River South site in northern California subjected to the 1989 Loma Prieta earthquake. At this site, the thickness of the surface nonliquefiable layer is unusually high $(6.6 \mathrm{~m})$, with the criterion developed by Ishihara (1985) predicting that surface manifestations would not have occurred even if the site had liquefied in 1989 (see Fig. S2, Youd and Garris 1995). That is, there is a strong possibility that the site did liquefy in 1989, without showing surface manifestations with the two data points in Fig. 6 being misclassified as false positives. Therefore, these two case histories are not considered further herein.

2. The other 11 case histories, which are false positives in Fig. 6, are all located in the Imperial Valley of southern California.

Therefore, the rest of this section focuses on the Imperial Valley, including both these 11 cases and other case histories of natural sand sites in the valley that were subjected to earthquake shaking. There were five physical sites contributing to the list of case histories in Table S1: Heber Road Channel Fill, Heber Road Point Bar, McKim, Vail Canal, and Wildlife. The sites are located within a maximum distance of approximately $40 \mathrm{~km}$ from each other (Porcella et al. 1982, 1987). Fig. 6 includes all 37 case histories associated with these
Imperial Valley sites, and the 37 data points are plotted separately in Fig. 7, which again shows clearly the 11 false positives (relative to the original Andrus and Stokoe solid line). All 37 case histories in Fig. 7 are silty sands with nonplastic FCs between 6 and 34\%.

Fig. 7 strongly suggests that the natural silty sands in the Imperial Valley have a significantly higher liquefaction resistance than that predicted by either the original Andrus-Stokoe boundary solid lines in Figs. 1 and 2 or by the constant cyclic shear strain line in Fig. 5 that worked so well for the recent UFs. Before arriving at a final conclusion in this respect, the authors subjected these 11 false positives in Fig. 7 to detailed scrutiny in order to explore alternative explanations for the apparent increased liquefaction resistance exhibited by these sites. This scrutiny, which is available in Appendix S1, examines two possible explanations: (1) some or all the critical layers at these sites are not fully saturated, thus the increased liquefaction resistance could be lost if they became saturated in the future; and (2) the critical layers did liquefy but the case histories were misclassified as no liquefaction because of a thick nonliquefiable shallow layer that prevented observable surface manifestations such as sand boils or cracks. In addition, in Appendix S1 the implications of the fact that some of the case histories in Fig. 7 are not truly independent because they correspond to multiple $V_{s 1}$ measurements at the same physical site are discussed.

The evidence discussed in Appendix S1 reveals that the false positives in Fig. 7 are indeed cases of no liquefaction and were fully saturated, thus supporting the conclusion that the silty sand sites in the Imperial Valley have an increased liquefaction resistance. Especially compelling is Case History No. 110 in Table S1 (Case History $\mathrm{F}$ in Table S4 and Fig. S3). This case history, with $V_{s 1}$ $=147 \mathrm{~m} / \mathrm{s}$ and $(\mathrm{CSR})_{7.5}=0.13$, corresponds to the Wildlife site and the $2010 \mathrm{El}$ Mayor-Cucupah earthquake. The data point is the highest false positive in Fig. 7, with a clear prediction by both the Andrus and Stokoe and Kayen lines that the site should have liquefied. It did not, and piezometers at the site recorded a rather low maximum excess pore pressure ratio in the critical layer, $\left(r_{u}\right)_{\max }$ $=0.19$. In addition, this case history is unusually well documented

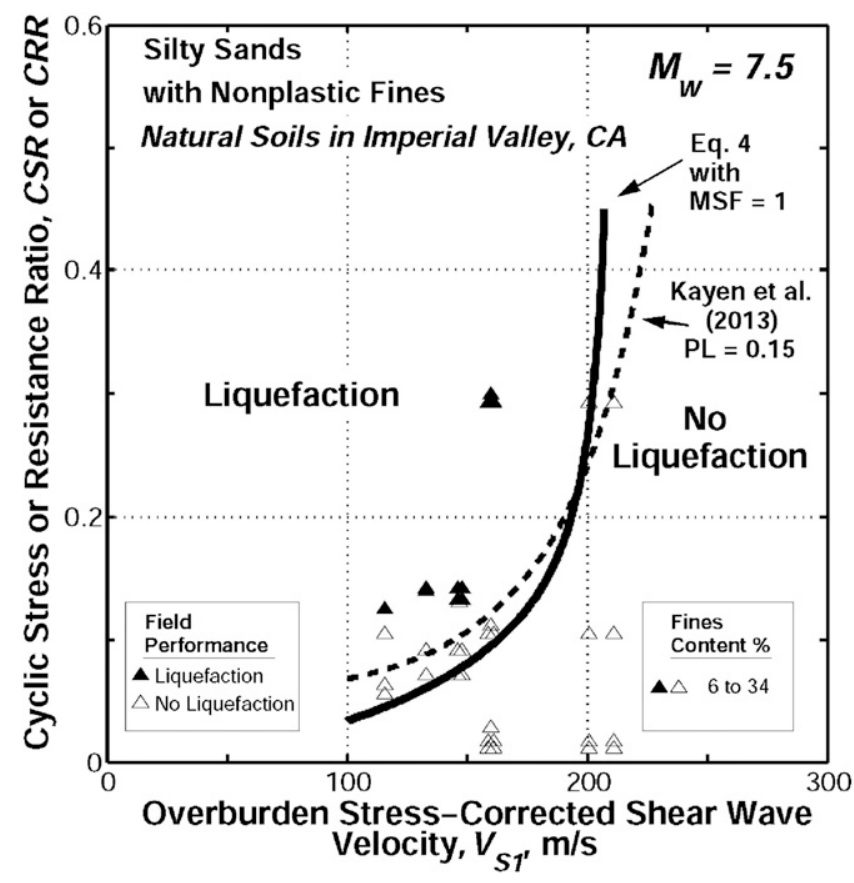

Fig. 7. Case histories of silty sands in the Imperial Valley of California: (NSs, 37 case histories) 
and has little uncertainty because (1) the depth to groundwater was measured just before the shaking from the piezometer readings; (2) the value of $V_{s 1}$ had been confirmed by crosshole measurements a few years before the earthquake by Cox (2006); and (3) both $a_{\max }$ and the nonoccurrence of liquefaction were obtained, respectively, from accelerometer and piezometer readings at the site instead of being inferred from attenuation relationships and the lack of surface manifestations such as sand boils.

Table 2 includes a comparison between this 2010 nonliquefaction case of a NS in the Imperial Valley, and the liquefaction case history of the UF at the Treasure Island Fire Station in the 1989 Loma Prieta earthquake. Both critical layers are silty sands of $V_{s 1} \quad 150 \mathrm{~m} / \mathrm{s}$ deposited 50-100 years before the earthquake, with the thickness of the layer in fact being greater in Wildlife, and with both being subjected to similar earthquake shaking intensity and duration associated with $a_{\max } \quad 0.13 g$ and $M_{\mathrm{w}} \quad 7$. Despite these similarities, while the UF at Treasure Island liquefied during the shaking, the natural sand at Wildlife had only a measured pore pressure ratio, $\left(r_{u}\right)_{\max }=0.19$, at the end of shaking. As discussed in Idriss (1990), De Alba et al. (1994), Power et al. (1998), and Andrus and Stokoe (2000), liquefaction at this Treasure Island site was detected based on a sudden drop in the recorded acceleration time history. No surface manifestations were observed because of the thick nonliquefiable layer above the layer that liquefied. Therefore, both this liquefaction at Treasure Island in 1989 and the no liquefaction at Wildlife in 2010 are based on instrumental records.

Fig. 8 includes a line of constant cyclic shear strain, $\gamma_{c l}$ $0.1-0.2 \%$ for $M_{\mathrm{w}}=7.5$, fitted to the 37 case histories of liquefaction and no liquefaction corresponding to the Imperial Valley sites. These are the same case histories plotted in Fig. 7. This curve has the equation

$$
\mathrm{CRR}=0.065 \mathrm{MSF}{\frac{V_{s 1}}{100}}^{2}
$$

where MSF $=1$ in Fig. 8, and $V_{s 1}$ is in meters per second. The fact that this curve corresponds to a range of cyclic shear strains, $\gamma_{c l} \quad 0.1-0.2 \%$ for MSF $=1$ and $M_{\mathrm{w}}=7.5$, was established using Eq. (6) with $\sigma_{v 0}^{\prime}=50 \mathrm{kPa}$ (the average value of $\sigma_{v 0}^{\prime}$ for the Imperial Valley sites), and the calculation procedure described by Dobry and Abdoun (2011), including assumption of a range of values of the coefficient of lateral stress at the sites, $K_{0}=0.5-1.0$. These $\gamma_{c l}$

$0.1-0.2 \%$ values are several times greater than the $\gamma_{c l} \quad 0.03 \%$ cyclic shear strain needed to liquefy recent UFs (Fig. 5). The curve recommended for UFs in Fig. 5 is also included in Fig. 8. The comparison shown in Fig. 8 [as well as by Eqs. (7) and (8)] reveals that the natural silty sands in the Imperial Valley have a liquefaction resistance that is almost exactly twice the resistance of recent uncompacted clean or silty sandy fills $(0.065 / 0.033 \quad$ 2). Eq. (8) and Fig. 8 are recommended for practical use in the Imperial Valley of southern California. Possible extension of this recommendation to other areas requires a better understanding of the factor(s) causing this increased resistance.

\section{Preshaking of Natural Sands in the Imperial Valley}

All case histories for the Imperial Valley in the original Andrus et al. (2003) database are classified as geologically recent $(\leq 500$ years old). More specific radiocarbon information from a wood fragment from the Wildlife site in the Imperial Valley, taken at a depth of $6 \mathrm{~m}$ at the bottom of the liquefiable layer, yielded a date of $230 \pm 130$ years, which is an upper bound for the age of the layer

Table 2. Comparison between Liquefaction Responses of Wildlife and Treasure Island Sites

\begin{tabular}{|c|c|c|c|}
\hline Case history features & Feature & $\begin{array}{c}\text { Treasure Island Fire Station } \\
\text { site (San Francisco Bay area, } \\
\text { northern California) }\end{array}$ & $\begin{array}{l}\text { Wildlife site (Imperial } \\
\text { Valley, southern California }\end{array}$ \\
\hline \multirow[t]{9}{*}{ Site feature } & Deposit type & Artificial fill & NS \\
\hline & Deposition process & Hydraulic fill & Alluvial/fluvial \\
\hline & Year of deposition & Mid-1930s & $1905-1907 ?$ \\
\hline & $\begin{array}{l}\text { Thickness of critical } \\
\text { liquefiable layer }(\mathrm{m})\end{array}$ & 2.5 & 4.3 \\
\hline & $\begin{array}{l}\text { Thickness of nonliquefiable } \\
\text { surface layer }(\mathrm{m})\end{array}$ & 4.5 & 2.5 \\
\hline & Groundwater level depth (m) & 1.4 & \\
\hline & $\sigma_{v 0}^{\prime}(\mathrm{kPa})$ & 60.9 & 53.9 \\
\hline & Nonplastic FC (percentage) & 24 & 27 \\
\hline & $V_{s 1}(\mathrm{~m} / \mathrm{s})$ & $145-155$ & $146-148$ \\
\hline \multirow[t]{7}{*}{ Earthquake shaking feature } & Earthquake name and year & 1989 Loma Prieta & 2010 El Mayor-Cucupah \\
\hline & $\begin{array}{l}\text { Case history numbers in } \\
\text { Table S1 }\end{array}$ & $82-90$ & 110 \\
\hline & $M_{\mathrm{w}}$ & 7.0 & 7.2 \\
\hline & $\begin{array}{l}\text { Peak ground surface } \\
\text { acceleration, } a_{\max }(g)\end{array}$ & 0.13 & 0.134 \\
\hline & $(\mathrm{CSR})_{7.5}$ & 0.11 & 0.13 \\
\hline & Years since deposition & $\sim 55$ & $\sim 105$ \\
\hline & $\begin{array}{l}\text { Years since last liquefaction } \\
\text { event }\end{array}$ & $\sim 55$ (never liquefied before) & 23 \\
\hline Site liquefaction response & - & $\begin{array}{l}\text { Liquefied during shaking } \\
\text { (from recorded ground } \\
\text { surface accelerogram) }\end{array}$ & $\begin{array}{l}\text { Did not liquefy } \\
{\left[\left(r_{u}\right)_{\max }=0.19 \text { at end of }\right.} \\
\text { shaking from piezometric } \\
\text { recording }]\end{array}$ \\
\hline
\end{tabular}




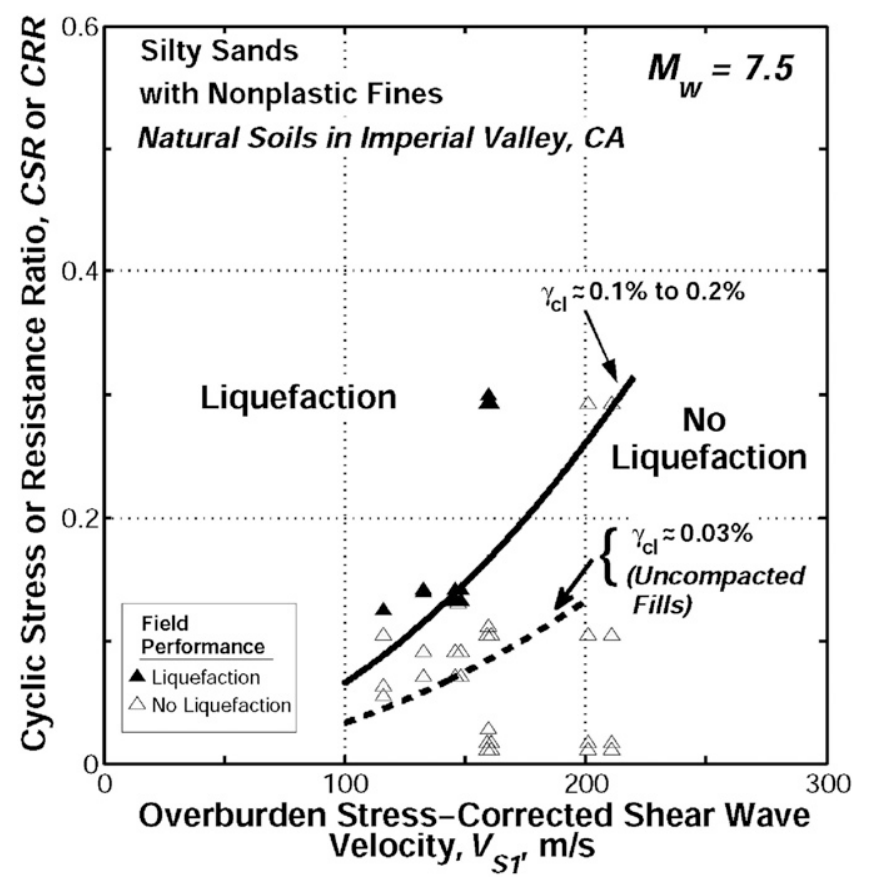

Fig. 8. Proposed constant cyclic shear strain liquefaction chart calibrated with the field case histories of natural silty sands in the Imperial Valley of California (37 case histories): the (solid line) curve for the Imperial Valley corresponds to Eq. (8) with $\mathrm{MSF}=1$ and $\mathrm{CRR}=0.065$ $\left(V_{s 1} / 100\right)^{2}$, associated with $\gamma_{c l} \quad 0.1-0.2 \%$; the dashed-line curve for clean and silty uncompacted sandy fills and $\gamma_{c l} \quad 0.03 \%$ is reproduced from Fig. 5, which has an expression given by Eq. (7) with MSF $=1$ and $\mathrm{CRR}=0.033\left(V_{s 1} / 100\right)^{2}$

(Bennett et al. 1984; Holzer and Youd 2007). Holzer and Youd (2007) suggest that most or all of the sediment in the critical liquefiable layer may have been deposited by flooding in 1905-1907. Under this hypothesis, the Wildlife liquefiable layer would be as young as some of the artificial fills in the San Francisco Bay area discussed in this paper (see Youd and Wieczoreck 1984). Furthermore, calculation of the possible effect of aging of the liquefiable layers in the Imperial Valley during their 100-200 year life since deposition, using the procedures proposed by Arango et al. (2000) and Hayati and Andrus (2009), predict small increases in liquefaction resistance, which are far from explaining the observed doubling of resistance between the two curves in Fig. 8. The comparison in Table 2 discussed in the previous section of liquefaction and no liquefaction, respectively, for comparable case histories of an UF in San Francisco and a natural sand site in the Imperial Valley having similarly short geologic ages since deposition (55 versus 105 years), also suggests that the increased liquefaction resistance in the Imperial Valley is not a result of geologic age. The most probable explanation for this increased liquefaction resistance in the Imperial Valley is preshaking of the natural sand sites there by the high seismic activity that characterizes the valley.

There is no doubt that the seismic activity in the Imperial Valley in the last century or so has been very high, certainly more intense than in the San Francisco Bay area for the same period. This exceptionally high seismic activity in the Imperial Valley is illustrated by both the twentieth-century historic evidence and the recordings from the Wildlife site accelerometers and piezometers since their installation in 2005. At least six earthquakes with magnitudes between 5.5 and 6.3 shook the Imperial Valley between 1900 and 1930 (Johnson and Hill 1982). More than 30 earthquakes with magnitudes greater than 5 occurred in the subsequent 50 -year period between approximately 1930 and 1980; with liquefaction observed at least in four of these events (Youd and Wieczoreck 1984; Dobry et al. 1992). The sites associated with the case histories plotted in Fig. 8 have been significantly affected by activity of local faults, including especially the Brawley Fault Zone located close to the Wildlife and Vail Canal sites. Youd et al. (2007) reported that six earthquakes in the last 7580 years generated observed liquefaction effects at or within $10 \mathrm{~km}$ of Wildlife. Much of this activity was caused by the nearby Brawley Fault Zone, which periodically generates swarms (sequences of earthquakes in a short time period). Swarms were reported in this zone in 1975, 1976, 1977, 2005, and 2012 (Johnson and Hadley 1976; Johnson and Hill 1982; Hauksson et al. 2013).

The sites included in Figs. 7 and 8 were affected by four significant earthquakes between 1979 and 1987; sometimes liquefying and other times not liquefying the corresponding site. At the Wildlife site, all four events had measured or estimated peak ground surface horizontal accelerations, $a_{\max }>0.10 \mathrm{~g}$, presumably generating excess pore-water pressures in all cases in the critical layer (El-Sekelly 2014). The array installed since 2005 at the Wildlife site recorded 13 earthquakes between 2005 and 2014 with $a_{\max } \geq 0.10 \mathrm{~g}$. While all 13 events generated excess pore pressures, none liquefied the site. More than half of these earthquakes were associated with the 2012 Brawley swarm, corresponding to small-magnitude, short-duration, and large-acceleration/significant pore pressure buildup events.

It seems reasonable to conclude that in the last century the Wildlife site must have been shaken by a number on the order of 60 70 earthquakes, all having an acceleration at the site approximately equal to or greater than $0.10 \mathrm{~g}$, with most of these events causing a pore pressure buildup short of liquefaction and a few liquefying the site (J. M. Steidl, personal communication, 2013; El-Sekelly 2014). Contrast this with a typical site in the San Francisco Bay area, where most of the artificial fills used to develop the constant strain chart in Fig. 5 are located. The seismic activity in the San Francisco Bay area was much smaller in the twentieth century after the 1906 earthquake [Applied Technology Council (ATC) 2005; Petersen et al. 2008], with an estimated number of earthquake shakings having $a_{\max }$ $>0.10 \mathrm{~g}$ at a hypothetical site probably not exceeding 5-10. Also, there were very few reported cases of liquefaction throughout the area in the 83-year period between the 1906 San Francisco and 1989 Loma Prieta earthquakes (Youd and Hoose 1978). Therefore, even if it is assumed that the sedimentation process at deposition created similar types of sand fabric at the two sites compared in Table 2 in the San Francisco Bay area and Imperial Valley (hydraulic filling versus alluvial/fluvial deposition), the seismic history after deposition was very different for the two sites, with the Wildlife site experiencing dozens of earthquakes causing pore pressure buildup, while the Treasure Island Fire Station site experienced only a few.

There is clear laboratory evidence indicating that preshaking by several earthquake events can increase very significantly the liquefaction resistance of sand (Finn et al. 1970; Seed et al. 1977; Seed 1979). On the other hand, if the soil is allowed both to liquefy and develop large strains, the subsequent liquefaction resistance may be decreased rather than increased (Finn et al. 1970). Heidari and Andrus (2012) observed that full liquefaction may completely erase the beneficial effects of geologic aging and preshaking in increasing liquefaction resistance, thus resetting the clock and bringing the resistance of the sand to the value it had when the deposit was still young. Centrifuge and large-scale shaking tests, including multiple events, suggest that the phenomenon is not simple but rather complex, with most of the shaking events strengthening the liquefiable layer and some weakening it (El-Sekelly 2014). For a given site and for the Imperial Valley seismic environment, the behavior in the long run (after many shakings including some that induced liquefaction) seems 
to have been a significant net increase in liquefaction resistance. This is strongly suggested by the Wildlife site response to the El MayorCucupah earthquake listed in Table 2, as well as by the rest of the Imperial Valley case histories plotted in Fig. 8.

\section{Discussion}

The constant cyclic shear strain liquefaction boundary proposed in Fig. 8, which takes advantage of the increased liquefaction resistance caused by intense preshaking in a short geologic time period, is recommended by the authors only for sites in the Imperial Valley. These sites in the Imperial Valley are characterized by very young natural silty sands affected by a specific and very intense seismic environment in the last century. As discussed in the previous section, the San Francisco Bay area had a much slower rate of occurrence of preshaking seismic events in the same time period, thus the chart in Fig. 8 is not applicable to sites in and around San Francisco. Extrapolation of the findings from Fig. 8 to natural silty sand deposits located in seismic areas outside the Imperial Valley will typically require careful consideration of the actual geologic age and seismic history experienced by the critical liquefiable layer.

The authors suggest that more studies be conducted to broaden the database of case histories of uncompacted recent fills, CFs, and natural sites to include a wider variety of geographical seismic areas in California, as well as Japan and other countries. This work may be accomplished by revisiting the large existing database relating liquefaction potential to $V_{s 1}$ developed by Kayen et al. (2013), and going back to relevant literature sources to compile the necessary information on soil type and geologic history of the critical layer. The results can then be used to further validate the proposed chart for UFs in Fig. 5, as well as to compare the liquefaction potential of natural sites from areas having different geologic ages and seismic environments, with the chart for the Imperial Valley in Fig. 8. Similar revisiting of SPT and CPT case history databases and separate plotting of clean and silty sands, as well as further segregation by type of soil and geologic history as done in Figs. 3 and $5-8$, are also suggested to investigate the possibility of separate SPT and CPT charts that discriminate more precisely between various types of deposits (e.g., Cetin et al. 2004; Moss et al. 2006; Idriss and Boulanger 2010; Boulanger et al. 2012). In addition, further laboratory and field research is recommended toward clarification of the specific factors causing the observed increased liquefaction resistance of natural sands, such as geologic age and preshaking by previous earthquakes.

\section{Conclusions}

Three main conclusions are reached from examination of the separate plots for recent artificial UFs and natural sandy soils in Figs. 3 and 6, plus additional considerations:

1. The original clean sand curve proposed by Andrus and Stokoe (2000), defined by Eq. (4) and plotted in Fig. 3, separates reasonably well liquefaction from no liquefaction for the UFs in the database. However, the scarcity of data points in the database in the CSR $=0.04-0.09$ range makes it difficult to locate the liquefaction/no-liquefaction boundary line only from the field case histories. Cyclic shear strain considerations and use of additional case histories from large-scale and centrifuge tests allow narrowing the search for the location of the boundary (Fig. 5). Finally, the line of constant cyclic shear strain defined by Eq. (7) and plotted in Fig. 5 ( $\gamma_{c l} \quad 0.03 \%$ for $M_{\mathrm{w}}=7.5$ ), is recommended in practical applications for evaluation of the liquefaction potential of recent uncompacted sand fills up to nonplastic FC $34 \%$.
2. The original Andrus and Stokoe (2000) clean sand CRR curve is too conservative for the geologically recent natural silty sands in the database located in the Imperial Valley of southern California (Fig. 7). The new proposed constant strain curve for UFs included in Fig. 5 is also found to be too conservative for the Imperial Valley sites. This increased liquefaction resistance of natural sands versus UFs is consistent with field observations after earthquakes in California and Japan reported in the literature, and seems to be associated mainly with preshaking by the numerous earthquakes that have shaken the Imperial Valley during the life of the deposits. The line of constant cyclic shear strain defined by Eq. (8) and plotted in Fig. $8\left(\gamma_{c l} \quad 0.1-0.2 \%\right.$ for $\left.M_{\mathrm{w}}=7.5\right)$, is recommended in practical applications for liquefaction evaluation of these natural silty sands in the Imperial Valley but not necessarily for other areas characterized by different geologic ages and seismic activities.

3. Two types of additional studies are recommended to generalize the results of this paper. They are as follows:

a. Development of a geographically diverse database of clean and silty sands case histories segregated by deposit type and geologic/seismic environment, using both $V_{s}$ and penetration resistance measured in uncompacted recent fills, CFs, and NS sites; and

$b$. Further laboratory and field research toward clarification of the specific factors causing the observed increased liquefaction resistance of natural sands discussed in the paper, such as geologic age and preshaking by previous earthquakes.

These two types of studies can then be combined to produce a new generation of liquefaction charts and procedures that account more realistically for deposit type, seismic history, and geologic age.

\section{Acknowledgments}

The authors are very grateful to a number of colleagues for their valuable contributions to the process of preparing this paper: Ronald Andrus, Ignacio Arango, Thomas Holzer, Brady Cox, Waleed ElSekelly, Geoff Martin, Vicente Mercado, Maurice Power, Robert Pyke, Walter Silva, Jamison Steidl, and T. Leslie Youd. The support of the National Science Foundation and the Network for Earthquake Engineering Simulation under NESSR-SG Grant No. 0529995 is also gratefully acknowledged.

\section{Supplemental Data}

Tables S1-S4, Figs. S1-S3, and Appendix S1 are available online in the ASCE Library (www.ascelibrary.org).

\section{References}

Abdoun, T., et al. (2013). "Centrifuge and large-scale modeling of seismic pore pressures in sands: Cyclic strain interpretation." J. Geotech. Geoenviron. Eng., 10.1061/(ASCE)GT.1943-5606.0000821, 1215-1234.

Andrus, R. D., and Stokoe, K. H., II. (2000). "Liquefaction resistance of soils from shear-wave velocity." J. Geotech. Geoenviron. Eng., 10.1061/ (ASCE)1090-0241(2000)126:11(1015), 1015-1025.

Andrus, R. D., Stokoe, K. H., II, Chung, R. M., and Juang, C. H. (2003). Guidelines for evaluating liquefaction resistance using shear wave velocity measurement and simplified procedures, U.S. Dept. of Commerce, Materials and Construction Research Division, Gaithersburg, MD.

Applied Technology Council (ATC). (2005). "San Francisco earthquake risk." San Francisco Dept. of Building Inspection Community Action Plan for Seismic Safety Rep., Redwood City, CA. 
Arango, I., Lewis, M. R., and Kramer, C. (2000). "Updated liquefaction potential analysis eliminates foundation retrofitting of two critical structures." Soil. Dyn. Earthquake Eng., 20(1-4), 17-25.

Arango, I., and Migues, R. E. (1996). Investigation of the seismic liquefaction of old sand deposits, Bechtel, San Francisco.

Baxter, C. D. P., and Mitchell, J. K. (2004). "Experimental study on the aging of sands." J. Geotech. Geoenviron. Eng., 10.1061/(ASCE)1090-0241 (2004)130:10(1051), 1051-1062.

Bennett, M. J., McLaughlin, P. V., Sarmiento, J. S., and Youd, T. L. (1984). "Geotechnical investigations of liquefaction sites, Imperial Valley, California." Open-File Rep. 84-252, USGS, Menlo Park, CA.

Bierschwale, J. G., and Stokoe, K. H., II. (1984). "Analytical evaluation of liquefaction potential of sands subjected to the 1981 Westmorland Earthquake." Geotechnical Engineering Rep. GR-84-15, Civil Engineering Dept., Univ. of Texas at Austin, Austin, TX.

Boulanger, R. W., and Idriss, I. M. (2011). "Cyclic failure and liquefaction: Current issues." Proc., 5th Int. Conf. on Earthquake Geotechnical Engineering, Chilean Geotechnical Society, Santiago, Chile, 137-159.

Boulanger, R. W., Wilson, D. W., and Idriss, I. M. (2012). "Examination and reevaluation of SPT-based liquefaction triggering case histories." $J$. Geotech. Geoenviron. Eng., 10.1061/(ASCE)GT.1943-5606.0000668, 898-909.

Cetin, K. O., et al. (2004). "Standard penetration test-based probabilistic and deterministic assessment of seismic soil liquefaction potential." J. Geotech. Geoenviron. Eng., 10.1061/(ASCE)1090-0241(2004)130:12(1314), 1314-1340.

Cox, B. R. (2006). "Development of direct test method for dynamically assessing the liquefaction resistance of soils in situ." Ph.D. thesis, Univ. of Texas at Austin, Austin, TX.

Cox, B. R., et al. (2013). "Liquefaction at strong motion stations and in Urayasu City in the 2011 Great East Japan Earthquake." Earthquake Spectra, 29(S1), S55-S80.

Darendeli, M. B. (2001). "Development of a new family of normalized modulus reduction and material damping curves." Ph.D. thesis, Univ. of Texas at Austin, Austin, TX.

De Alba, P., Benoit, J., Pass, D. G., Carter, J. J., Youd, T. L., and Shakal, A. F. (1994). "Deep instrumentation array at the Treasure Island Naval Station." The Loma Prieta, California, Earthquake of October 17, 1989Strong ground motion, R. D. Borcherdt, ed., Vol. 1551-A, U.S. Printing Office, Washington, DC, A155-A168.

Dobry, R. (1989). "Some basic aspects of soil liquefaction during earthquakes." Earthquake hazards and the design of constructed facilities in the eastern United States, K. H. Jacob and C. J. Turkstra, eds., Vol. 558, Annals of the New York Academy of Sciences, New York Academy of Sciences, New York, 172-182.

Dobry, R., and Abdoun, T. (2011). "An investigation into why liquefaction charts work: A necessary step toward integrating the states of art and practice." Proc., 5th Int. Conf. on Earthquake Geotechnical Engineering, Chilean Geotechnical Society, Santiago, Chile, 13-44.

Dobry, R., Abdoun, T., Thevanayagam, S., El-Ganainy, H., and Mercado, V. (2013). "Case histories of liquefaction in loose sand fills during the 1989 Loma Prieta Earthquake: Comparison with large scale and centrifuge shaking tests." Proc., 7th Int. Conf. on Case Histories in Geotechnical Engineering, S. Prakash, ed., Missouri Univ. of Science and Technology, Rolla, MO.

Dobry, R., Baziar, M. H., O'Rourke, T. D., Roth, B. L., and Youd, T. L. (1992). "Liquefaction and ground failure in the Imperial Valley during the 1979, 1981 and 1987 earthquakes." Case studies of liquefaction and lifeline performance during past earthquakes: United States case studies, T. D. O'Rourke and M. Hamada, eds., Vol. 2, National Center for Earthquake Engineering Research, Buffalo, NY, 1-85.

El-Sekelly, W. E. (2014). "The effect of seismic preshaking history on the liquefaction resistance of granular soil deposits." Ph.D. thesis, Dept. of Civil and Environmental Engineering, Rensselaer Polytechnic Institute, Troy, NY.

Finn, W. D. L., Bransby, P. L., and Pickering, D. J. (1970). "Effect of strain history on liquefaction of sand.” J. Soil Mech. and Found. Div., 96(6), 1917-1934.

Geoengineering Extreme Events Reconnaissance (GEER). (2010a). "Geotechnical reconnaissance of the 2010 Darfield (New Zealand)
Earthquake." NSF-Sponsored Rep. No. GEER-024, R. A. Green and M. Cubrinovski, eds., Version 1, National Science Foundation, Arlington, VA.

Geoengineering Extreme Events Reconnaissance (GEER). (2010b). "Geoengineering reconnaissance of the 2010 Maule, Chile Earthquake." NSF-Sponsored Rep. No. GEER-022, J. Bray and F. Frost, eds., Version 2, National Science Foundation, Arlington, VA.

Geoengineering Extreme Events Reconnaissance (GEER). (2011a). "Geoengineering reconnaissance of the 2011 Christchurch, New Zealand Earthquake.” NSF-Sponsored Rep. No. GEER-027, M. Cubrinovski, R. A. Green, and L. Wotherspoon, eds., Version 1, National Science Foundation, Arlington, VA.

Geoengineering Extreme Events Reconnaissance (GEER). (2011b). "Geotechnical quick report on the Kanto plain region during the March 11, 2011, off Pacific Coast of Tohoku Earthquake, Japan." GEER Association Rep. No. GEER-025a, National Science Foundation, Arlington, VA.

Green, R. A., et al. (2011) "Geotechnical aspects of failures at Port-au-Prince Seaport during the 12 January 2010 Haiti Earthquake." Earthquake Spectra, 27(S1), S43-S65.

Hauksson, E., et al. (2013). "Report on the August 2012 Brawley Earthquake swarm in Imperial Valley, Southern California." Seismol. Res. Lett., 84(2), 177-189.

Hayati, H., and Andrus, R. D. (2008). "Liquefaction potential map of Charleston, South Carolina based on the 1886 earthquake." J. Geotech. Geoenviron. Eng., 10.1061/(ASCE)1090-0241(2008)134:6(815), 815-828.

Hayati, H., and Andrus, R. D. (2009). "Updated liquefaction resistance correction factors for aged sands." J. Geotech. Geoenviron. Eng., 10.1061/(ASCE)GT.1943-5606.0000118, 1683-1692.

Heidari, T., and Andrus, R. D. (2012). "Liquefaction potential assessment of Pleistocene beach sands near Charleston, South Carolina." J. Geotech. Geoenviron. Eng., 10.1061/(ASCE)GT.1943-5606.0000686, 1196-1208.

Holzer, T. L., and Youd, T. L. (2007). "Liquefaction, ground oscillation, and ground deformation at the Wildlife Array, California." Bull. Seismol. Soc. Am., 97(3), 961-976.

Hossain, A. M., Andrus, R. D., and Camp, W. M., III. (2013). "Correcting liquefaction resistance of unsaturated soil using wave velocity." $J$. Geotech. Geoenviron. Eng., 10.1061/(ASCE)GT.1943-5606.0000770, 277-287.

Hsu, C.-C., and Vucetic, M. (2004). "Volumetric threshold shear strain for cyclic settlement." J. Geotech. Geoenviron. Eng., 10.1061/(ASCE) 1090-0241(2004)130:1(58), 58-70.

Idriss, I. M. (1990). "Response of soft soil sites during earthquakes." Proc., H. Bolton Seed Memorial Symp., Vol. 2, BiTech, Vancouver, BC, Canada, 273-289.

Idriss, I. M., and Boulanger, R. W. (2004). "Semi-empirical procedures for evaluating liquefaction potential during earthquakes." Proc., 3rd Int. Conf. on Earthquake Geotechnical Engineering, D. Doolin, A. Kammerer, T. Nogami, R.B. Seed, and I. Towhata, eds., Vol. 1, Univ. of California, Berkeley, CA, 32-56.

Idriss, I. M., and Boulanger, R. W. (2008). "Soil liquefaction during earthquakes." Monograph MNO-12, Earthquake Engineering Research Institute, Oakland, CA.

Idriss, I. M., and Boulanger, R. W. (2010). "SPT-based liquefaction triggering procedures." Rep. UCD/CGM-10/02, Dept. of Civil and Environmental Engineering, Univ. of California, Davis, CA.

Ishihara, K. (1985). "Stability of natural deposits during earthquakes." Proc., 11th Int. Conf. on Soil Mechanics and Foundation Engineering, Vol. I, Balkema, Rotterdam, Netherlands, 321-376.

Ishihara, K., Araki, K., and Bradley, B. A. (2011). "Characteristics of liquefaction-induced damage in the 2011 Great East Japan Earthquake." Proc., Int. Conf. on Geotechnics for Sustainable Development, Univ. of Canterbury, Christchurch, New Zealand.

Johnson, C. E., and Hadley, D. M. (1976). "Tectonic implications of the Brawley Earthquake swarm, Imperial Valley, California, January 1975." Bull. Seismol. Soc. Am., 66(4), 1133-1144.

Johnson, C. E., and Hill, D. P. (1982). "Seismicity of the Imperial Valley." The Imperial Valley California Earthquake of October 15, 1979, USGS, U.S. Government Printing Office, Washington, DC. 
Kayen, R., et al. (2013). "Shear-wave velocity-based probabilistic and deterministic assessment of seismic soil liquefaction potential." $J$. Geotech. Geoenviron. Eng., 10.1061/(ASCE)GT.1943-5606.0000743, 407-419.

Leon, E., Gassman, S. L., and Talwani, P. (2006). “Accounting for soil aging when assessing liquefaction potential." J. Geotech. Geoenviron. Eng., 10.1061/(ASCE)1090-0241(2006)132:3(363), 363-377.

Lewis, M. R., Arango, I., Kimball, J. K., and Ross, T. E. (1999). "Liquefaction resistance of old sand deposits." Proc., 11th Pan-American Conf. on Soil Mechanics and Geotechnical Engineering, International Society for Soil Mechanics and Geotechnical Engineering, London, 821-829.

Liu, N., and Mitchell, J. K. (2006). "Influence of nonplastic fines on shear wave velocity-based assessment of liquefaction." J. Geotech. Geoenviron. Eng., 10.1061/(ASCE)1090-0241(2006)132:8(1091), 1091-1097.

Moss, R. E., Seed, R. B., Kayen, R. E., Stewart, J. P., Der Kiureghian, A., and Cetin, K. O. (2006). "CPT-based probabilistic and deterministic assessment of in situ seismic soil liquefaction potential." J. Geotech. Geoenviron. Eng., 10.1061/(ASCE)1090-0241(2006)132:8(1032), 1032-1051.

Moss, R. E. S., Thornhill, D. M., Nelson, A. I., and Levulett, D. A. (2008). "Influence of aging on liquefaction potential: Preliminary results." Proc., Geotechnical Earthquake Engineering and Soil Dynamics IV, Geotechnical special publication 181, D. Zeng, M. T. Manzari, and D. R. Hiltunen, eds., ASCE, Reston, VA, 1-10.

National Research Council (NRC). (1985). Liquefaction of soils during earthquakes, R. V. Whitman, ed., National Academy Press, Washington, DC.

Olson, S. M., et al. (2011). "Documenting liquefaction and lateral spreading triggered by the 12 January 2010 Haiti Earthquake." Earthquake Spectra, 27(S1), S93-S116.

Peck, R. B. (1979). "Liquefaction potential: Science versus practice." $J$. Geotech. Engrg. Div., 105(3), 393-398.

Petersen, M. D., et al. (2008). "Documentation for the 2008 update of the United States national seismic hazard maps." Open-File Rep. 2008 1128, USGS, Reston, VA.

Porcella, R. L., Etheredge, E., Maley, R., and Switzer, J. (1987). "Strongmotion data from the Superstition Hills Earthquakes 0154 and 1315 (GMT), Nov. 24, 1987." Open-File Rep. 87-672, USGS, Menlo Park, CA.

Porcella, R. L., Matthiesen, R. B., and Maley, R. P. (1982). "Strong-motion data recorded in the United States." The Imperial Valley California Earthquake October 15, 1979, USGS, U.S. Government Printing Office, Washington, DC, 289-318.

Power, M. S., Egan, J. A., Shewdridge, S. E., deBecker, J., and Faris, J. R. (1998). "Analysis of liquefaction-induced damage on Treasure Island." The Loma Prieta, California, Earthquake of October 17, 1989Liquefaction, strong ground motion and ground failure, T. L. Holzer, ed., USGS, U.S. Government Printing Office, Washington, DC, B87-B119.

Pyke, R. (2003). "Discussion of 'Liquefaction resistance of soils: Summary report from the 1996 NCEER and 1998 NCEER/NSF workshops on evaluation of liquefaction resistance of soils' by T. L. Youd, I. M. Idriss, Ronald D. Andrus, Ignacio Arango, Gonzalo Castro, John T. Christian, Richardo Dobry, W. D. Liam Finn, Leslie F. Harder Jr., Mary Ellen Hynes, Kenji Ishihara, Joseph P. Koester, Sam S. C. Liao, William F. Marcuson III, Geoffrey R. Martin, James K. Mitchell, Yoshiharu Moriwaki, Maurice S. Power, Peter K. Robertson, Raymond B. Seed, and Kenneth H. Stokoe II." J. Geotech. Geoenviron. Eng., 10.1061/ (ASCE)1090-0241(2003)129:3(283), 283-284.

Richart, F. E., Hall, J. R., and Wood, R. D. (1970). Vibrations of soils and foundations, Prentice Hall, Englewood Cliffs, NJ.

Robertson, P. K., Woeller, D. J., and Finn, W. D. L. (1992). "Seismic cone penetration test for evaluating liquefaction potential under cyclic loading." Can. Geotech. J., 29(4), 686-695.
Schneider, J. A., and Moss, R. E. S. (2011). "Linking cyclic stress and cyclic strain based methods for assessment of cyclic liquefaction triggering in sands." Geotech. Lett., 1(2), 31-36.

Seed, H. B. (1979). "Soil liquefaction and cyclic mobility evaluation for level ground during earthquakes." J. Geotech. Engrg. Div., 105(2), 201255.

Seed, H. B., Chan, C. K., and Mori, K. (1977). "Influence of seismic history on liquefaction of sands." J. Geotech. Engrg. Div., 103(4), 257-270.

Seed, H. B., and Idriss, I. M. (1970). "Soil moduli and damping factors for dynamic response analyses." Rep. EERC 70-10, Earthquake Engineering Research Center, Univ. of California, Berkeley, CA.

Seed, H. B., and Idriss, I. M. (1971). "Simplified procedure for evaluating soil liquefaction potential." J. Soil Mech. and Found. Div., 97(9), 12491273 .

Seed, H. B., Idriss, I. M., and Arango, I. (1983). "Evaluation of liquefaction potential using field performance data." J. Geotech. Engrg., 10.1061/ (ASCE)0733-9410(1983)109:3(458), 458-482.

Steidl, J. M., and Seale, S. H. (2010). "Observations and analysis of ground motions and pore pressure at the NEES instrumented geotechnical field sites." Proc., 5th Int. Conf. on Recent Advances in Geotechnical Earthquake Engineering and Symp. in Honor of Professor I. M. Idriss, S. Prakash, ed., Missouri Univ. of Science and Technology, Rolla, MO.

Troncoso, J., Ishihara, K., and Verdugo, R. (1988). "Ageing effects on cyclic shear strength of tailing materials." Proc., 9th World Conf. on Earthquake Engineering, Vol. 3, International Association for Earthquake Engineering (IAEE), Tokyo, 121-126.

Umberg, D. (2012). "Dynamic properties of soils with non-plastic fines." M.S. thesis, Univ. of Texas at Austin, Austin, TX.

Vucetic, M. (1986). "Pore pressure buildup and liquefaction at level sand sites during earthquakes." Ph.D. thesis, Dept. of Civil Engineering, Rensselaer Polytechnic Institute, Troy, NY.

Youd, T. L., et al. (2001). "Liquefaction resistance of soils: Summary report from the 1996 NCEER and 1998 NCEER/NSF workshops on evaluation of liquefaction resistance of soils." J. Geotech. Geoenviron. Eng., 10.1061/(ASCE)1090-0241(2001)127:10(817), 817-833.

Youd, T. L., et al. (2003). "Closure to 'Liquefaction resistance of soils: Summary report from the 1996 NCEER and 1998 NCEER/NSF workshops on evaluation of liquefaction resistance of soils' by T. L. Youd, I. M. Idriss, Ronald D. Andrus, Ignacio Arango, Gonzalo Castro, John T. Christian, Richardo Dobry, W. D. Liam Finn, Leslie F. Harder Jr., Mary Ellen Hynes, Kenji Ishihara, Joseph P. Koester, Sam S. C. Liao, William F. Marcuson III, Geoffrey R. Martin, James K. Mitchell, Yoshiharu Moriwaki, Maurice S. Power, Peter K. Robertson, Raymond B. Seed, and Kenneth H. Stokoe II." J. Geotech. Geoenviron. Eng., 10.1061/(ASCE)1090-0241(2003)129:3(284), 284-286.

Youd, T. L., and Garris, C. T. (1995). "Liquefaction-induced ground-surface disruption.” J. Geotech. Engrg., 10.1061/(ASCE)0733-9410(1995)121: 11(805), 805-809.

Youd, T. L., and Hoose, S. N. (1977). "Liquefaction susceptibility and geologic setting." Proc., 6th World Conf. on Earthquake Engineering, Indian Society of Earthquake Technology, Roorkee, India, 2189-2194.

Youd, T. L., and Hoose, S. N. (1978). "Historic ground failures in northern California triggered by earthquakes." Geological Survey Professional Paper 993, U.S. Dept. of the Interior, Washington, DC.

Youd, T. L., and Perkins, D. M. (1978). "Mapping liquefaction-induced ground failure potential." J. Geotech. Engrg. Div., 104(4), 433-446.

Youd, T. L., Steidl, J. H., and Steller, R. A. (2007). "Instrumentation of the wildlife liquefaction array." Proc., Int. Conf. on Earthquake Geotechnical Engineering, K. D. Pitilakis, ed., Springer, Dordrecht, Netherlands.

Youd, T. L., and Wieczoreck, G. F. (1984). "Liquefaction during the 1981 and previous earthquakes near Westmorland, California." Open-File Rep. 64-680, USGS, Menlo Park, CA. 